\title{
أثر استخدام استر اتيجية تدريسية قائمة على عادات العقل في تطوير الكفاءة الرياضية لدى طلبة المرحلة الأسـاسية في الأردن
}

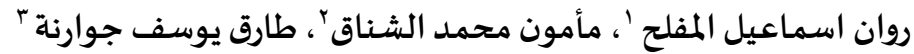 \\ ' طالبة في جامعة اليرموك- كلية التربية- قسم المناهج وطرق التدريس- الأردن

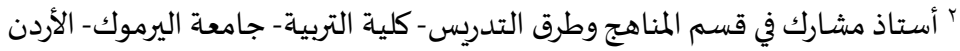

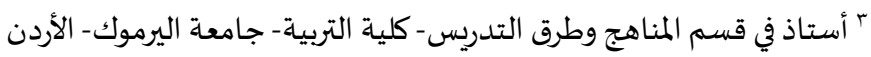

1 rawanshdifat92@gmail.com,2 mamoon.shannaq@yu.edu.jo,3 tjawarneh@yu.edu.jo

هدفت هذه الدراسة إلى معرفة أثر استخدام استراتيجية تدريسية قائمة على عادات العقل في تطوير الكفاءة الرياضية لدى طلبة المرحلة الأسـاسية في الأردن. ولتحقيق هذا الهدف؛ أعد الباحثون اختباراً في الكفاءة الرياضية وتحققوا من صدقدهـ وثباته. تم اختيار عينة متيسرة تتكون من (عV) واحدة تتكون من (Y0) طالبة بشكل عشوائي كمجموعة تجريبية، وتم تدريسها وحدة الجبر باستخدام استراتيجية تدريسية قائمة على عادات العقل. أما المجموعة الأخرى والتي تتكون من (rr) طالبة تم تعيينها كمجموعاة ضابطة وتم تدريسها وحدة الجبر باستخدام الطريقة الاعتيادية. تم تطبيق

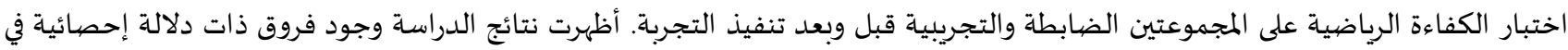

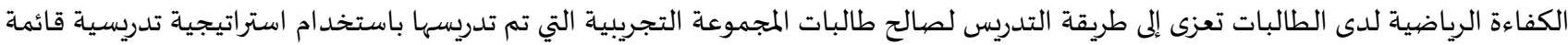
على عادات العقل. وفي ضوء نتائج الدراسة أوصى الباحثون بتعريف معلمي الرياضيات بعادات العقل واستخدافها في تدريس الرياضيات. الكلمات المفتاحية: عادات العقل؛ الكفاءة الرياضية؛ استراتيجية تدريس.

\section{() ()}

المقدمة:

في ظل التقدم الحاصل في جميع مناحي الحياة، وتوفر السبل المتعددة التي ساهمت بتقدم طرق التعلّم وتحديداً في مجال الرياضيات، والتي كان

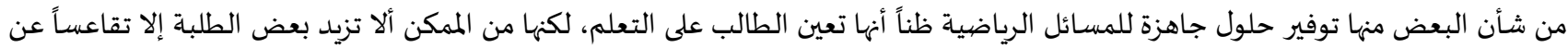

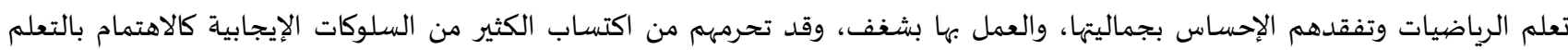

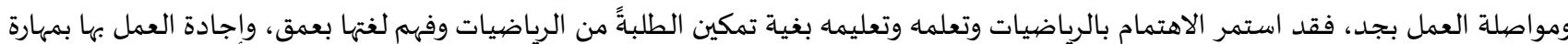
وكفاءة، وتوظيفها بدقة. رغم ذلك، ينظر العديد من الطلبة إلى الرياضيات على أنها مجموعة من الحقائق والقواعد والصيخ المربكة والمخيبة للآمال، بسبب كثرة المفاهيم

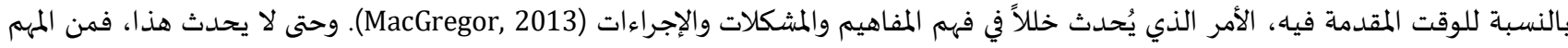

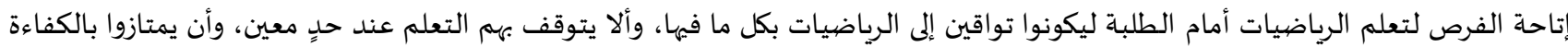

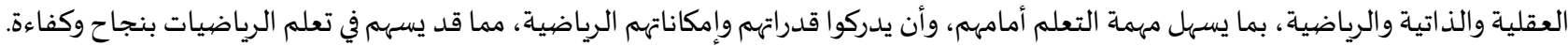

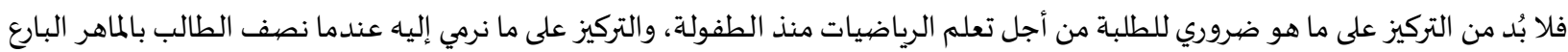
الكفؤ رياضياً، وهذا ما دعا إليه المجلس القومي للبحوث (National Research Council, 2001) عندما أشار إلى أبعاد وفروع الكفاءة الرياضية التي

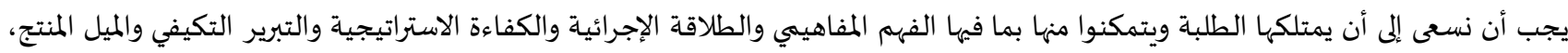


National Council of ) وقد دعت معايير الرياضيات المدرسية في مبادئها التعليمية إلى ضرورة التركيز على الفهم المفاهيمي من أجل فهم الرياضيات (Teachers of Mathematics, 2000 وتُعد الكفاءة سلوكاً معرفياً وتمثيلاً عقلياً منظماً للمعلومات والخبرات، وترتبط بطرق تسهل الاسترجاع للمعرفة والتطبيق المناسب لها، والكفاءة

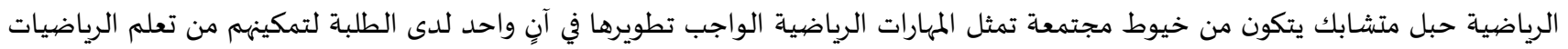
بنجاح، وتتمثل تلك المهارات بالفهم المفاهيمي والطلاقة الإجرائية والكفاءة الاستراتيجية والتبرير التكيفي والتصرف (الميل) المنتج (NRC,2001). ولأن الرياضيات لا يمكن تعلمها دون ممارسات فكرية دقيقة فمن المهم العمل على تنظيم تلك الممارسات الفكرية لتوظيفها في التعلم، ولذلك قد ولد نكون بحاجة إلى استراتيجيات وأنماط وممارسات فكرية داعمة لتفكير الطالب وعمله ومشاركته النشطة والفاعلة للارتقاء بمستواه على الصعيد الأكاديمي والذاتي والاجتماعي.

وكواحدة من الممارسات الفكرية وأنماط السلوك الفكري التي قد يظهر من خلالها السلوك الإنتاجي (Costa \& Kallik, 2000) تتجلى أهمية

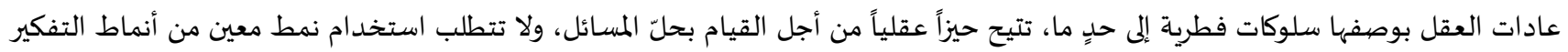

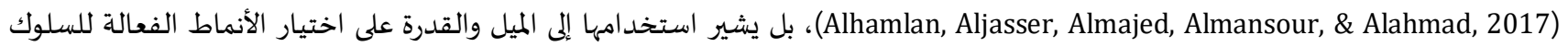

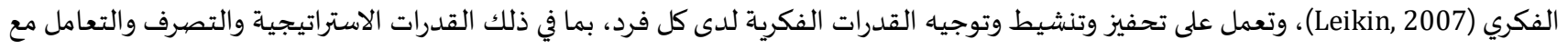

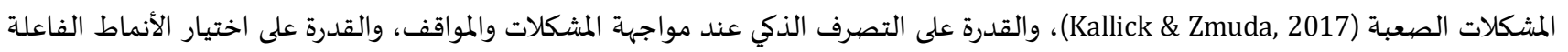

للسلوك الفكري (Leiken,2007)، وتحفيز الطلبة على الربط بين الأفكار الرياضية (Mark,Cuoco,Goldenberg\&Sword,1996). وهناك دعوات واضحة إلى التأكيد على التنوع في استخدام طرق التدريس، والتركيز على الفهم كمنطلق أساسي لتعلم الرياضيات وليس الحفظ

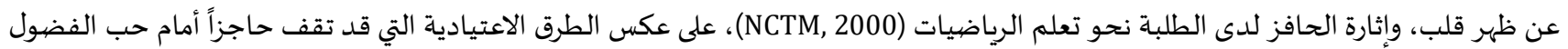
والاستطلاع لدى الطلبة أثناء تعلم الرياضيات.

الإطار النظري

مثلما أن الرياضيات مهمة للحياة، فإنها تدعم التطوير الشخصي، وتؤثر على عملية التعليم والتعلّم؛ فتطبيقها يمتد للعديد من المجالات، وهي

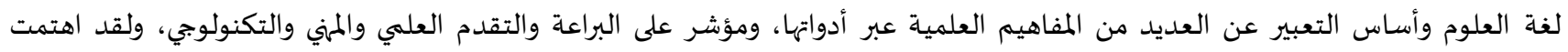

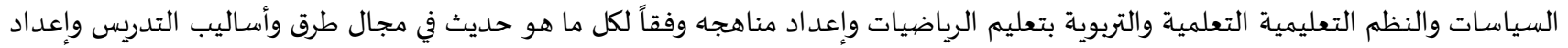
المعلم وتمكين الطلبة بما يضمن جودة نتاجاتها ومخرجاتها. فلم يعد النجاح في تعلم الرياضيات مقتصراً على إتقان الطلبة لتعلّم الإجراءات الحسابية وفهمها، أو القدرة على حل المشكلات واكتساب المهارات

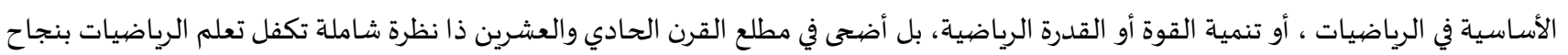

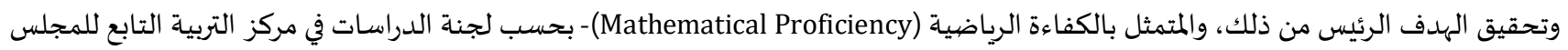

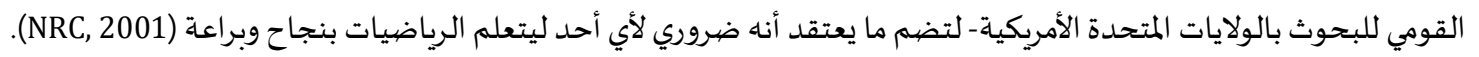

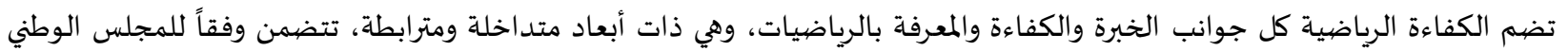
للبحوث (NRC, 2001):

الفهم المفاهيمي (Understanding Conceptual)، ويشير إلى إدراك المفاهيم والعلاقات والعمليات والإجراءات الرياضية، وتمثيل المواقف الرياضية بطرق مختلفة، والفهم المعمق لكيفية عمل الرياضيات، وهو يعزز الذاكرة والقدرة على الاحتفاظ بالمفاهيم وتطور الطلاقة الإجرائية.

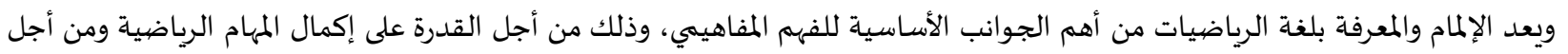
تحقيق النجاح في الرياضيات (MacGregor, 2013).

الطلاقة الإجرائية (Procedural Fluency)؛ وتتمثل بالقدرة على تنفيذ العمليات الحسابية والإجراءات الرياضية بدقة وكفاءة ومرونة وبشكل فعال وعلى نحو مناسب. تحتاج الطلاقة الإجرائية إلى معرفة عميقة ومرنة، ومجموعة متنوعة من الإجراءات، والقدرة على الحكم على الإجراءات أو الاستراتيجيات

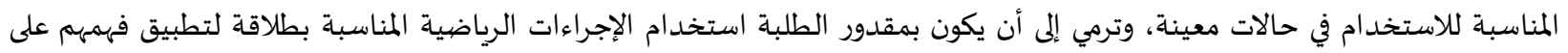
مشكلات العالم الحقيقي (NRC, 2001).

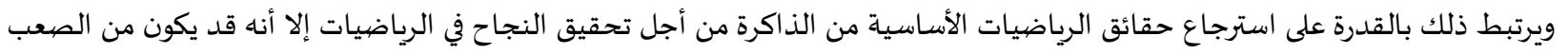

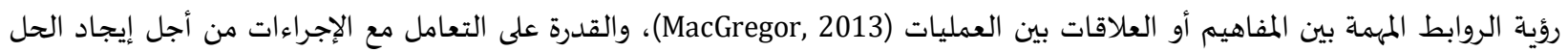


الصحيح للمشكلة؛ فهذه الأمور تتعلق بالتفكير كونه جزء مهم من الطلاقة الإجرائية وهو الأساس لاتخاذ القرار الذي يحتاج إليه الطالب في حل

المشكلة (Laswadi, Kusumah, Darwis, \& Afgani, 2016).

الكفاءة الاستراتيجية (Strategic Competence)، وتشير إلى القدرة على تفسير وصياغة المسائل الرياضية والقدرة على تمثيلها وحلها. وتتطلب الكفاءة الاستراتيجية وجود الفهم المفاهيمي لتقييم طبيعة المشكلة، والطلاقة الحسابية للقيام بحلّ المشكلة بدقة وكفاءة، ومن خلالها

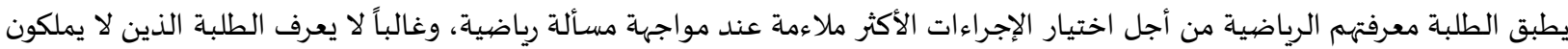

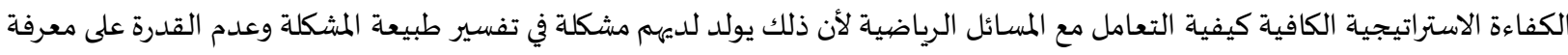
الاستراتيجية المناسبة للحل (MacGregor, 2013)، ومن الممكن الاهتمام بالكفاءة الاستراتيجية من خلال تعريض الطلبة الماتية لمشكلات رياضية

واقعية والتي تتطلب منهم الفهم ووضع خطة للحل وتنفيذها (Awofala,2017).

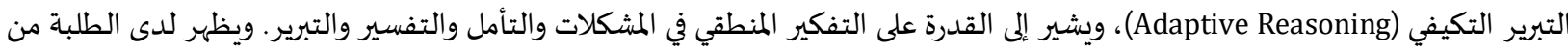
خلال قدرتهم على تبرير خطوات حل مشكلة ما ومعرفة مدى صحة الخطوات (Awofala,2017).

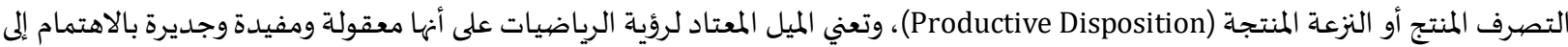
جانب الاعتقاد بالاجتهاد والفعالية والكفاءة الذاتية. ويذكر(Awofala,2017)" أن تطوير الكفاءة الرياضية ينطوي على اكتساب الطلبة القدرة على الانخراط في عادات العقل الرياضية الرياءية التي تعزز الفهم المفاهيمي والطلاقة الإجرائية والكفاءة الاستراتيجية والتبرير التكيفي". ولأجل حدوث التعلم المستمر وتحقيق النجاح فإنهاه يلزم توظيف عادات العقل كمهارات أساسية للحياة (Sommers \& Olsen,2010)،

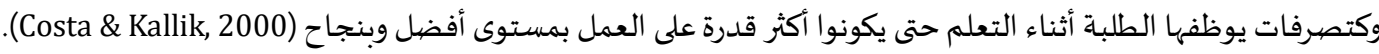

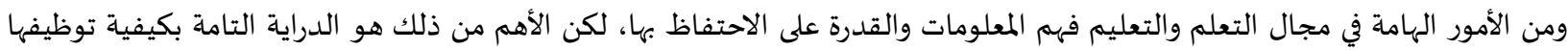

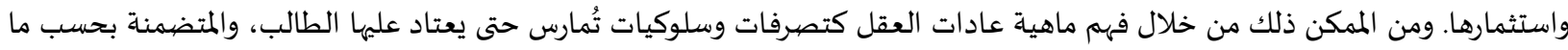
أشار كوستا وكاليك (Costa \& Kallik, 2000) ست عشرة عادة عقلية هي بمثابة سلوكيات ومواقف يمكن تطبيقها للتعلم وحل المشككلات، لا سيما عندما لا تكون المعلومات مفهومة تماماً، وهي: ا. الإصرار أو المثابرة (Persistence): وتشير إلى الالتزام بالمهمة المطلوبة حتى الانتهاء منها، والقدرة على تحليل المشكلة وتطوير الاستراتيجيات

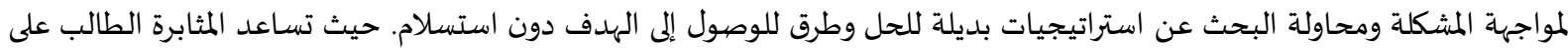
التمسك بالمشكلة الرياضية حتى ينجزها (Devaney \&Yahalem,2012). r. التحكم بالاندفاع (Managing Impulsivity): أي أخذ الوقت الكافي والتفكير قبل التصرف والحفاظ على الهدوء والتأني، وجمع المعلومات

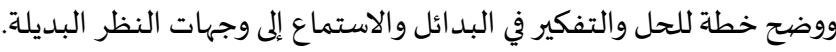
r. الإصغاء بتفهم وتعاطف (Listening with Empathy and Understanding)، وتعني تكريس الطاقة العقلية وبذل الجهد من أجل فهم أفكار الآخرين ووجهة نظرهم وتفهم مشاعرهم، دون سخرية أو مقاطعة أو تقليل من شأن الأفكار التي يطرحونها.

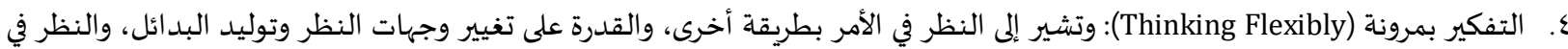
الخيارات المقترحة والمتاحة، ومعالجة المشكلة من زاوية جديدة. 0. التفكير حول التفكير، ما وراء المعرفة (Thinking about your Thinking Metacognition): أي إدراك وفهم المعرفة الخاصية والاستراتيجيات والمشاعر والأفعال، وتأثير ذلك كله على الآخرين، والقدرة على معرفة ما يعرفه المتعلم وما لا يعرفه من خلال وضع خطة إلى الداك للحل وخطوات واضحة وتقييمها بعد تطبيقها. آ. السعي من أجل الدقة (Striving for Accuracy): وتعني الكفاح من أجل التحقق مما تم تقديمه من طرق وحلول، وبذل قصهارى الجهد، وإيجاد طرق للتحسين باستمرار. V. تطبيق المعرفة السابقة في مواقف جديدة (Applying Past Knowledge to new situations): وتشير إلى استخدام ما تم تعلمه، ومحاولة

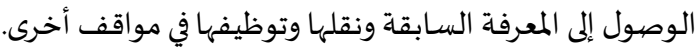

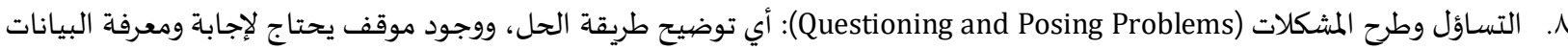

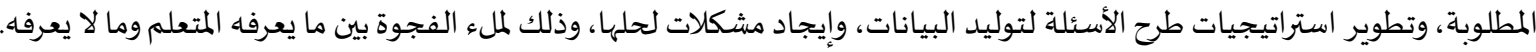

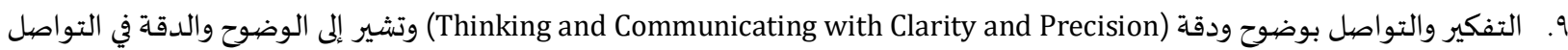
شفوياً أو كتابياً بلغة دقيقة، ومصطيلحات محددة وأسماء صحيحة. 
• ا. جمع البيانات باستخدام جميع الحواس (Gathering Data through All Sense)، وتعني استخدام المسارات الطبيعية الحسية التي تُدخل

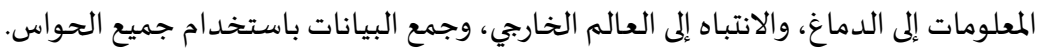

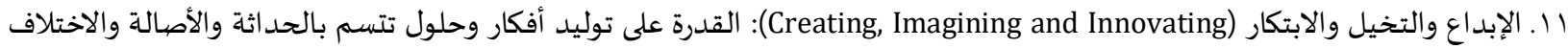
بوجود الدافع الذاتي والتحدي.

r ا. الاستجابة بدهشة ورهبة (Responding with Wonderment and Awe): جذب المتعلم بمواقف ومشككلات مثيرة للاهتمام، حيث يشعر المتعلم بالمتعة من خلال المعرفة وهذه المتعة ناتجة عن التحدي المتمثل بحل المشكلاتهات، وتلتكون لدياء الرغبة بالاستمرار في التعلم.

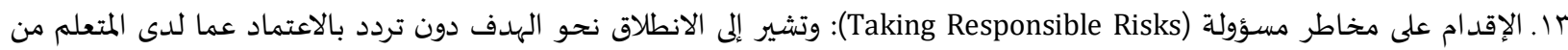
خبرات ومعارف سابقة، ودون أن يعتريه الإحباط عند مواجهة العقبات ودون الخوف من الفشل.

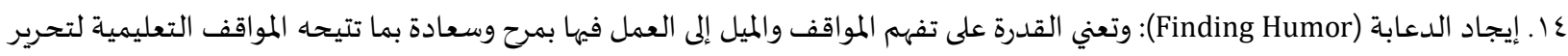
الإبداع وإثارة مهارات التفكير العليا. 10. التفكير التبادلي (Thinking Interdependently): العمل معاً بروح الفريق والاستجابة لهمه، والقدرة على العمل والتعلم ضمنمن مجموعات متعاونة وتبرير الأفكار وتبادلها مع الآخرين.

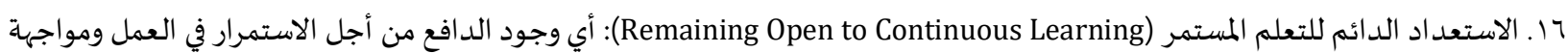
الخبرات التي يتعرضون وسيتعرضون لها، والاعتراف عند عدم وجود المعرفة للرغبة بالتعلم الجديد.

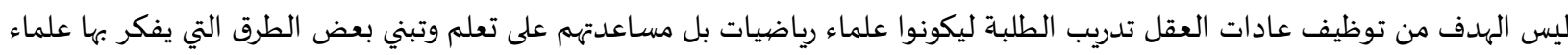
الرياضيات عندما يواجهون المشكلات، وأن يكونوا قادرين على استخدام أساليب رياضية حقيقية، والبحث، وتطوير الحدس وتقديم الأدلة الداعمة لذلك (Cuoco et al., 1996).

ولكون عادات العقل نمط للتفكير والتصرف بذكاء، ومساعدة الطلبة في المدرسة والحياة اليومية على مواجهة المشكلات والمعضضلات والحلول غير الواضحة وغير الجاهزة بشكل مباشر وتمارس حتى يعتادون عليها (Costa \& Kallik, 2000)، فإنها وبدلاً من أن يطالب المعلمون الطلبة بالتركيز فقط

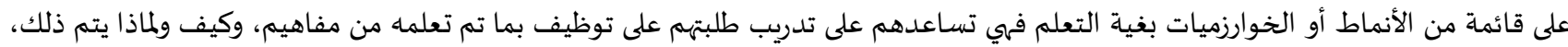
وهذا من خلال استثمار الفضيول وحب الاستطلاع والرغبة بتجربة طرق جديدة لدى الطلبة، والقيام بالمهام الرياضية وتقديم الأدلة والتفسيرات

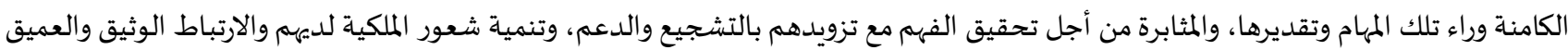
Massachusetts Department of (بما يقومون باء من مهام رياضية تقديراً لأهمية وقيمة هذه المهام، والتأمل الدائم بما تعلموه وبما يتعلق بهذا التعلمهاء

(Education, 2005

الدراسات السابقة: وأشارت العديد من الدراسات (Goldenberg,1996; Cuoco,et al.1996; Lim\& Selden,2009; Poindexter,2011) إلى أهمية دمج وتضمين عادات العقل في مناهج الرياضيات باستخدام أنشطة التعلم المناسبة؛؛ حيث أن الممارسين لها تحققت لهم مجموعاة من الخصائص كأن يفكروا كما

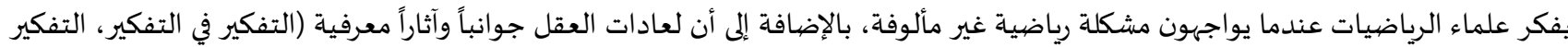

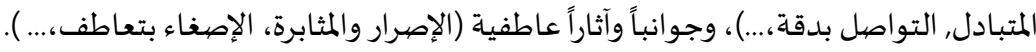

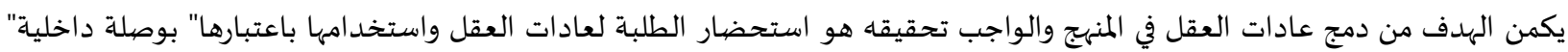
تعمل على توجياء أفكارهم وأفعالهم وقراراتهم في جميع مراحل التعليم المدرسي والحياة اليومية (Costa\& Kallick,2009).

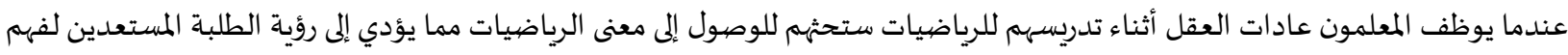

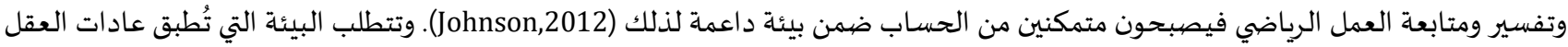

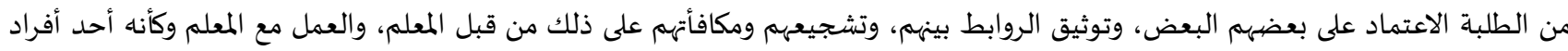

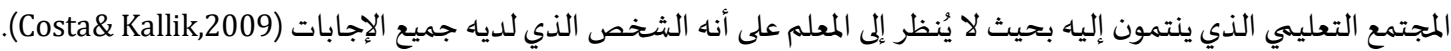
يمكن أن تسهم عادات العقل في تحقيق الكفاءة الرياضية لدى الطلبة؛ حيث أن المبدأ الأساسي لها يتمثل بالقدرة على التصرف بذكاء عند المداء

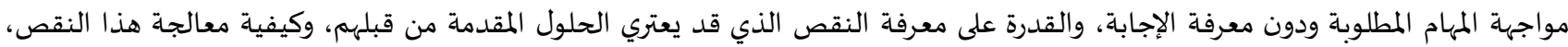

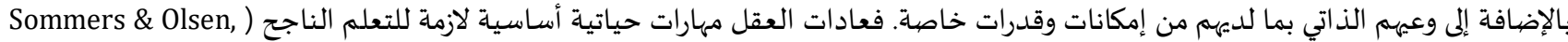

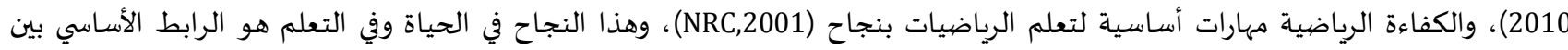
المتغيرات في الدراسة الحالية. ونظراً لأهمية هذه المتغيرات فقد تطرق الباحثون إلى إجراء الدراسات المتعلقة بها: 
هيث أجرت بصير (19 ـ r) دراسـة هدفت إلى التعرف على فعالية الأنشطة الإثرائية التي تستند على عادات العقل لتنمية التفكير الرياضي لدى الأطفال الموهوبين في مرحلة ما قبل المدرسة في المملكة العربية السعودية. تكونت عينة الدراسـة من مجموعة واحدة ضيمت (ع) أطفال موهوبين.

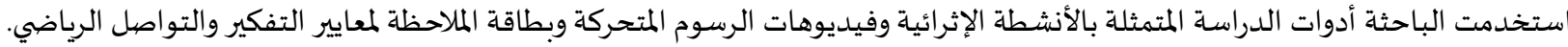
أسفرت النتائج عن وجود فرق ذي دلالة إحصائية بين متوسطي درجات الأطفال الموهوبين في تطبيق الملاحظة القبلية والبعدية لمعيار التفكير والاستدلال، ولمعيار التواصل الرياضي لصالح التطبيق البعدي للملاحظة. وأجرى التخاينة و أبو رياش (Atakhyneh\& Aburiash,2018) دراسة بهدف تقصي مستويات عادات العقل وأثرها في التفكير الإبداعي الرياضي

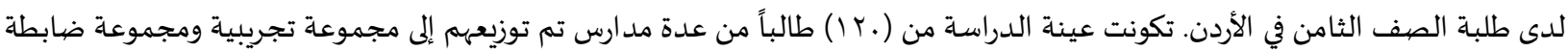
ضمت كل منها (. 7) طالباً، وقام الباحثان بتطوير مقياس عادات العقل وبرنامج تدريبي قائم على عادات العقل واختبار التفكير الإبدائ. أشارت

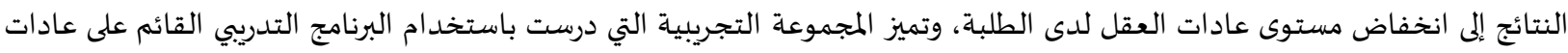
العقل على المجموعة الضابطة في اختبار التفكير الإبداعي، وأشارت إلى وجود علاقة ارتباطية إيجابية بين مستوى عادات العقل والتفكير دادي

الإبداعي.

وأجرى (Andriani, Yulianti, Ferdias \& Fatonah,2017) دراسة لمعرفة تأثير استراتيجية تعلم وفق عادات العقل القائمة على المشكلة على اتجاهات الطلبة نحو التفكير الإبداعي الرياضي لدى طلبة الصف السابع في إندونيسيا. تكونت عينة الدراسـة من (.V.) طالباً، تم تقسيم الطلبة

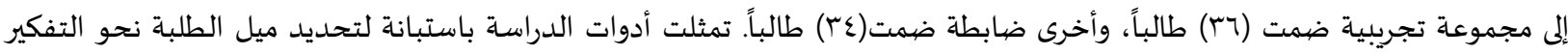
الإبداعي. أظهرت النتائج أن ميل الطلبة نحو التفكير الإبداعي في المجموعة التجريبية التي درست باستخدام عادات العقل القائمة على حل

المشكلة أفضل من ميل الطلبة في المجموعة الضابطة التي درست باستخدام الطريقة الاعتيادية(المرتكزة على المعلم). كما أجرى المقيد (2017) دراسة هدفت إلى التعرف إلى فاعلية برنامج مقترح قائم على عادات العقل في تنمية القوة الرياضية لدى طلاب الصف الرابع الأساسي في غزة. تكونت عينة الدراسة من (ع)) طالباً تم تقسيمهم إلى شعبتين دراسيتين، تجريبية وضابطة وتكونت كل منهما من (Yع)

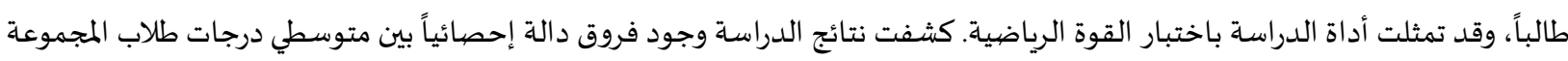
التجريبية وطلاب المجموعة الضابطة في التطبيق البعدي لاختبار القوة الرياضية لصالح المجموعة التجريبية. وقام السيد حسين (17) بإجراء دراسة هدفت إلى معرفة فاعلية برنامج قائم على عادات العقل في تعليم الرياضيات لتنمية التحصيل

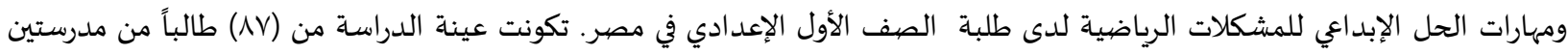

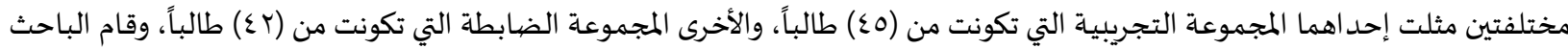

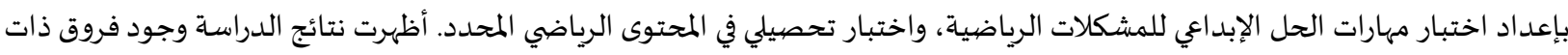
دلالة إحصائية بين أداء المجموعة التجريبية والضيابطة لصالح المجموعة التجريبية في اختبار التحصيل ككل، وفي اختبار مهارات الحل الإبداعي

للمشكلات الرياضية ككل.

وأجرت حليوه (10 ـ r) دراسـة هدفت إلى التعرف على أثر برنامج مقترح قائم على عادات العقل في تنمية القوة الرياضية وعملياتها لدى الطلبة

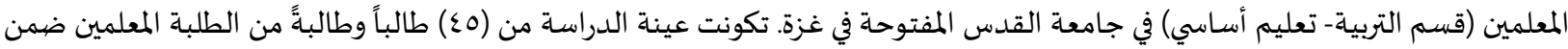
مجموعة واحدة، وأعدت الباحثة اختبار القوة الرياضياة بأبعاد التواصل الرياضي والترابط الرياضي والاستدلال الرياضي. أشارت نتائج الدراساة إلى وجود فروق ذات دلالة إحصائية بين متوسط درجات الطلبة في التطبيق القبلي والبعدي على الاختبار ككل وعلى كل بعد من أبعاد القوة الرياضية لصالح التطبيق البعدي وبحجم أثر مرتفع. وقام كل من المطرب والشوري (ع ا ـr) بإجراء دراسة هدفت إلى معرفة أثر استخدام برنامج عادات العقل في تنمية الذكاء المنطقي/ الرياضي

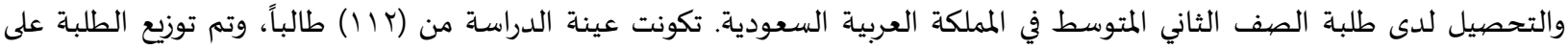

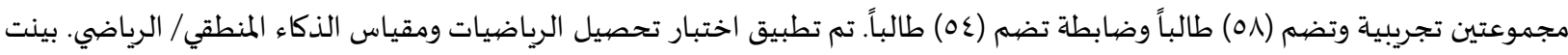
نتائج الدراسة أن ثمة فروق ذات دلالة إحصائية بين المجموعتين التجريبية والضابطة في تنمية التفكير المنطقي/ الرياضي لصالح المجموعة

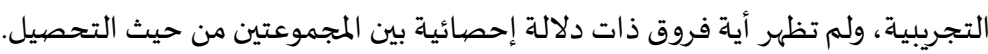

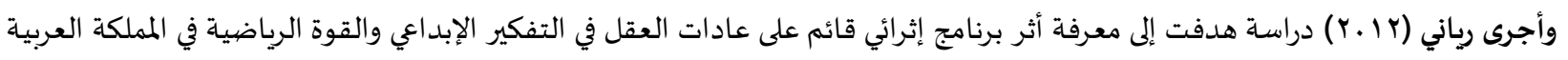

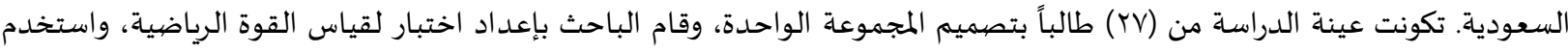
اختبار تورانس للتفكير الإبداعي. كشفت نتائج الدراسة عن وجود فروق ذات دلالة إحصائية بين متوسط درجات الطاتئ الطلبة في التطبيق القبلي والبعدي لاختبار التفكير الإبداعي ككل وفي كل مهارة من مهاراته لصالح التطبيق البعدي، وكشفت نتائج الدراسة أيضاً عن وجود فروق دالة

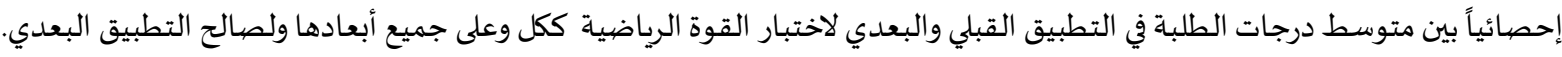




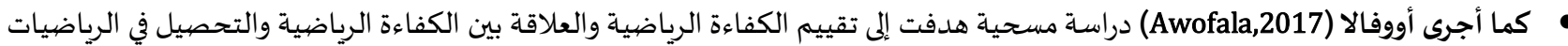

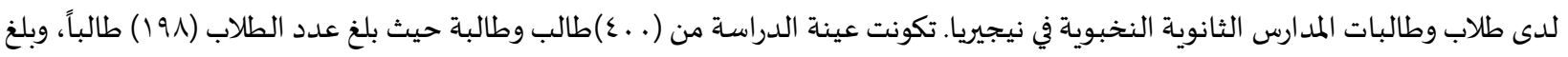
عدد الطالبات (Y .r) طالبة من الصف الأول الثانوي. جمع الباحث بيانات الدراسة باستخدام ست أدوات تمثلت باختبار الكفاءة الرياضية، وقائمة لمراجعة الفهه المفاهيمي، وقائمة لمراجعة الإجراءات، وقائمة لمراجعة الكفاءة الاستراتيجية، وقائمة لمراجعة التبرير التكيفي، وملاحظة

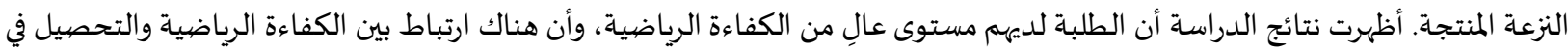
الرياضيات، ووجود فروق طفيفة في التحصيل في الرياضيات بين الطلاب والطالبات.

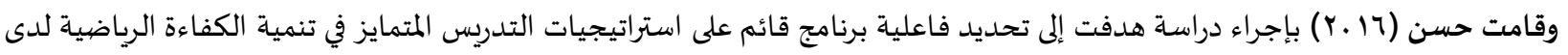
طلبة المرحلة الثانوية في مصر. وقد قامت الباحثة بتطبيق اختبار لفروع الكفاءة الرياضية (الفهم المفاهيمي والطلاقة الإجرائية والاستدلال

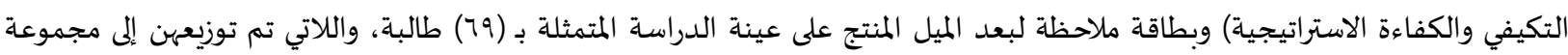

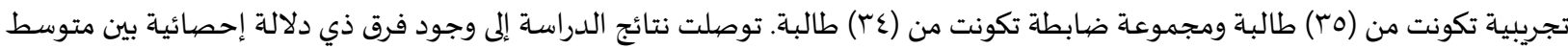

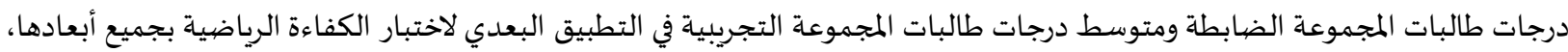
ولبطاقة ملاحظة الميل المنتج ولصالح المجموعة التجريبية.

وأجرى أبو الر ايات (ع ا ـ r) دراسـة هدفت إلى التعرف إلى فعالية نموذج أبعاد التعلم لمارزانو على تنمية الكفاءة الرياضية لدى طلبة الصف الأول

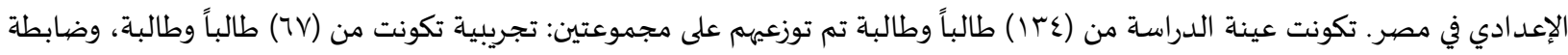
تكونت من العدد ذاته. أعد الباحث اختباراً لقياس أبعاد الكفاءة الرياضية المتمثلة بالفهه المفاهيهي والطلاقة الإجرائية والكفاءة الاستراتيجية منية

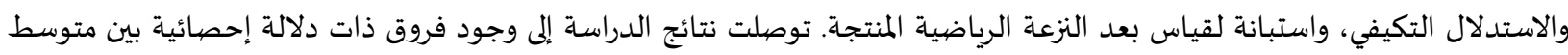

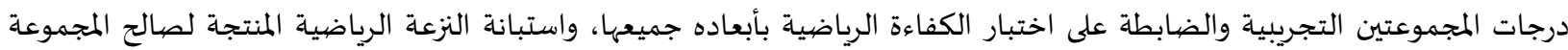
التجريبية. كما أجرت المصاروة (Y ا ـ Y) دراسة هدفت إلى التعرف على أثر التدريس وفق استراتيجية قائمة على الربط والتمثيل الرياضي في تنمية مهارات

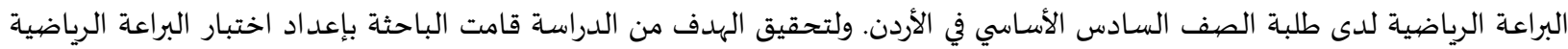
لمجالات الاستيعاب المفاهيمي والطلاقة الإجرائية والكفاءة الاستراتيجية والتفكير الاستدلالي، واستبانة لقياس مجال الميل المنتج، بالإضافة إلى الى المانيل

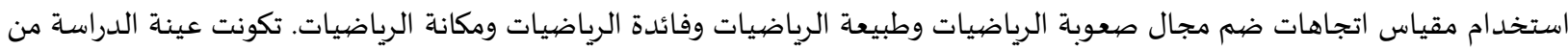

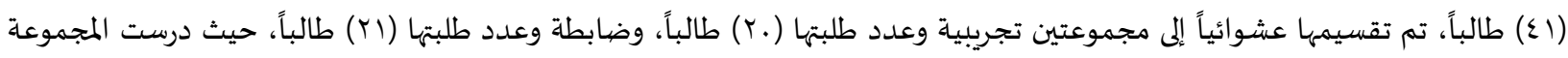

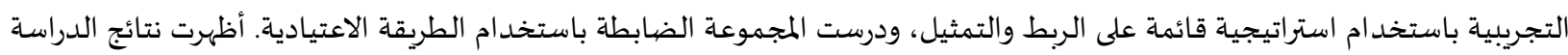

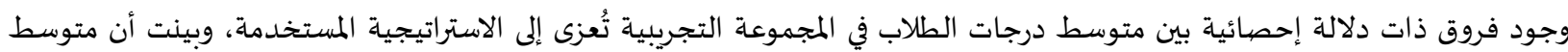

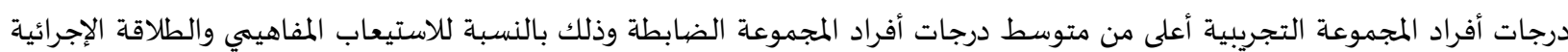

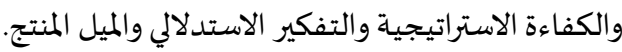

وأجرى ساميولسون (Samuelsson, 2010) دراسة هدفت الكشف عن تأثير المناهج التعليمية على الكفاءة الرياضية للطلبة في السويد من

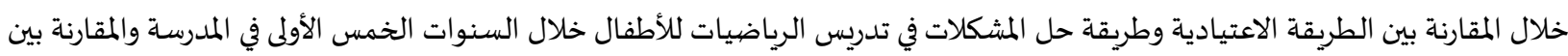

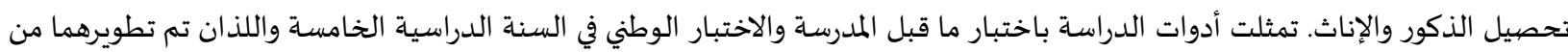

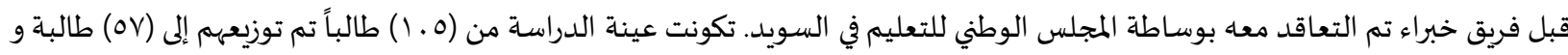

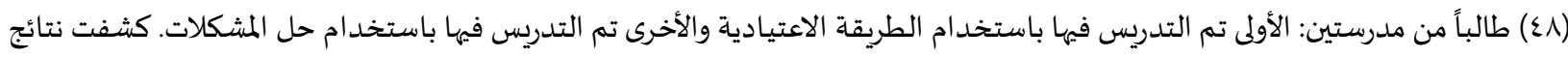

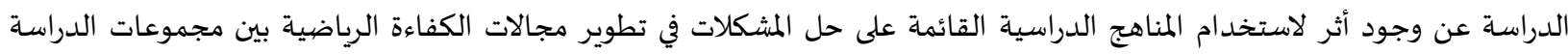

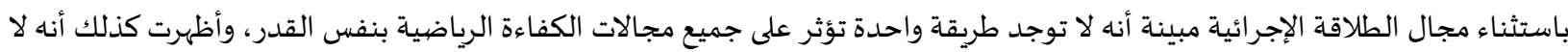

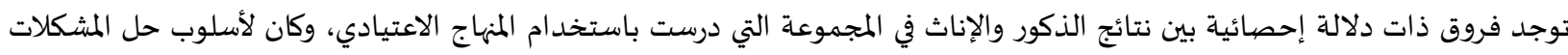
نفس التأثير على الذكور والإناث. التعقيب على الدراسـات السـابقة:

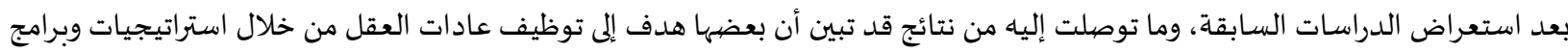

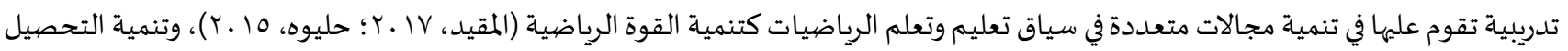

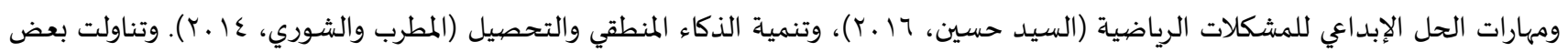




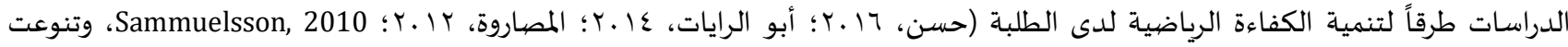
الدراسات في اختيارها للمرحلة الدراسية والعمرية والعقلية. وقد استفادت الدراسة الحالية من الدراسات السابقة باختيار المنهج الملائم لتحقيق أهدافها وتتمثل بالمنهج شباء التجريبي، واختيار استراتيجية

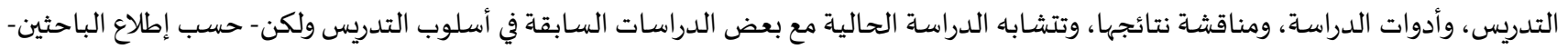
لا توجد دراسة قد وظفت عادات العقل في تطوير الكفاءة الرياضية.

مشكلة الدراسـة وأسئلتها:

Trends in International Mathematics and Science Study- (النظر إلى نتائج مشاركة طلبة الأردن في الاختبار الدولي للرياضيات والعلوم

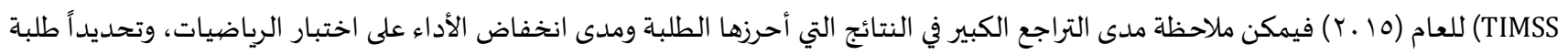

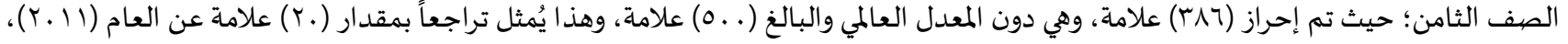

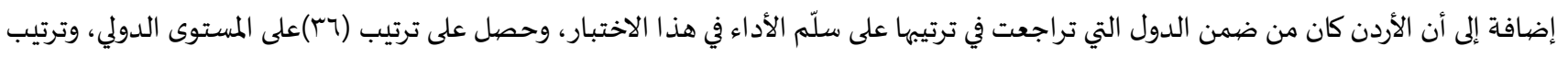

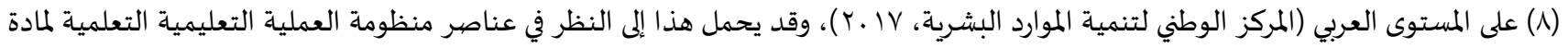

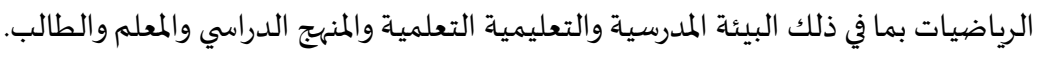
ولأن الطالب جزء من هذه المنظومة؛ فإنه ومن خلال اللقاء بمجموعة من طلبة الصف الثامن أشار العديد منهم إلى أنهم يقومون بالاطلاع على

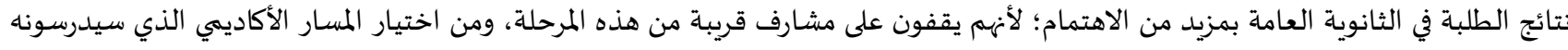

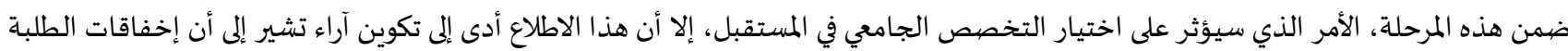
كانت بسبب مادة الرياضيات على الأغلب، وهذه الآراء السلبية كان لها السبب الأبرز في تكون الثقافة السائدة حول صعوبة مادئ مادة الرياضيات وفي تكون

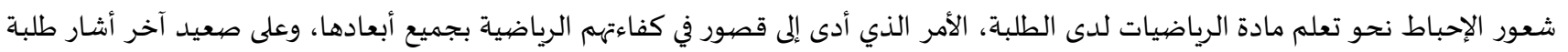

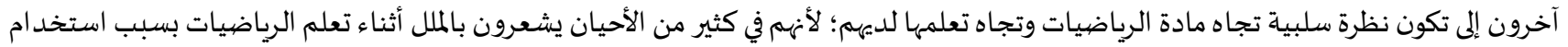

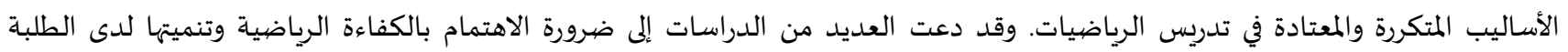

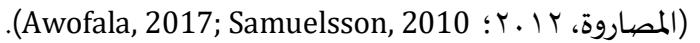

وبعد التواصل مع بعض المعلمين في الميدان التربوي وبالتحديد معلمي الصف الثامن، أكد المعلمون أنه ثمة مشكلة تتعلق بضعف الحافئ المافز والرغبة

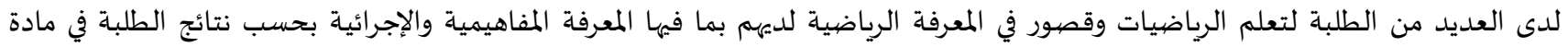

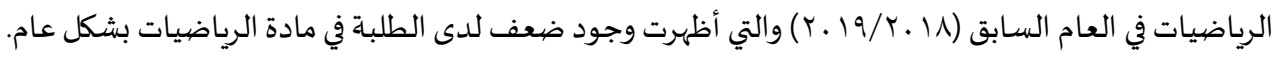

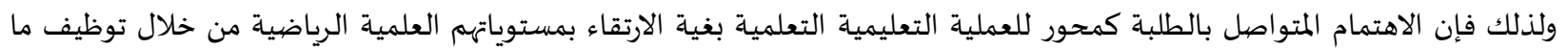

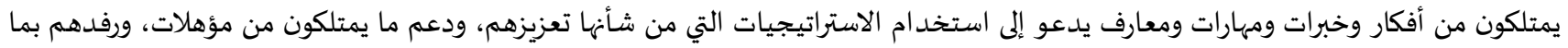

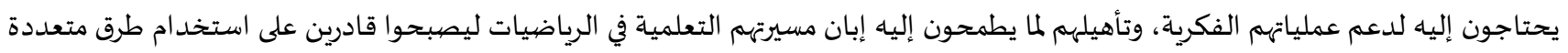
للوصول إلى استخدام الطريقة الأمثل والأكثر ملائمة حسب ما يقتضيه الموقف التعليهي الذي يواجهونها أو يتعرضون إليه، وقد يتحقق هذا من خلال استخدام عادات العقل في تدريس الرياضيات. أشارت نتائج الدراسات إلى أن من المهم التركيز على توظيف عادات اتديات العقل في مختلف الفروع والمجالات الرياضية ودعت إلى استخدامها في تدريس

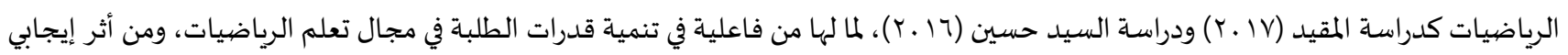
في تحسين سلوك الطلبة وتطوير أدائهم الأكاديمي (Costa \& Kallick, 2000).

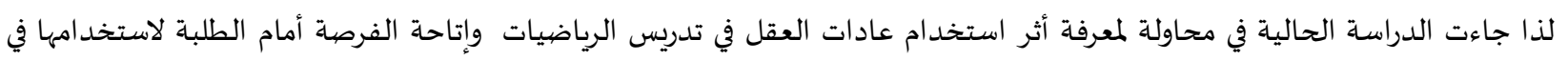

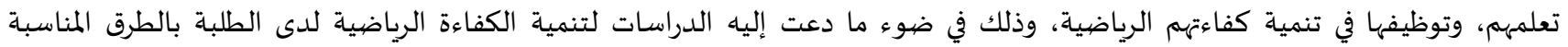

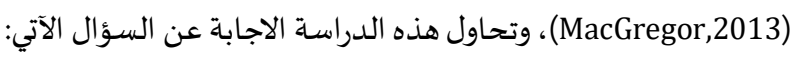

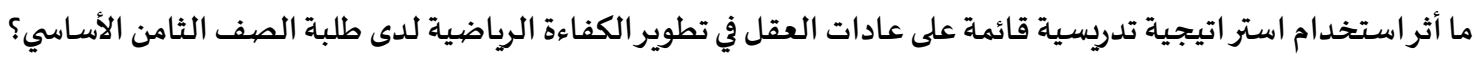
وانبثق عن سؤال الدراسة الفرضية الصفرية الآتية: "لا يوجد فرق ذي دلالة إحصائية بين متوسط علامات سوض الطالبات في المجموعة التجريبية ( اللواتي درسن باستخدام عادات العقل" ومتوسط علامات الطالبات في المجموعة الضابطة ( اللواتي درسن باستخدام الطريقة الاعتيادية) في اختبار الكفاءة الرياضية البعدي". 
تهدف الدراسة الحالية إلى تعرّف أثر استخدام استراتيجية تدريسية قائمة على عادات العقل في تطوير الكفاءة الرياضية لدى طلبة الصف

تنبثق أهمية الدراسة الحالية من الناحية النظرية والناحية التطبيقية.

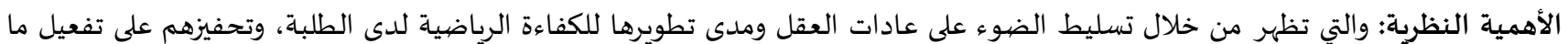
يمتلكون من عادات عقلية من أجل الارتقاء بأنفسهم في مجال تعليم وتعلم الرياضيات، ودعوة المعلمين إلى الاهتمام بعادات العقل والسعي نحو توظيفها في تدريس الرياضيات والاهتمام بها. ومن خلال توظيف الدراسـة الحالية لما لدى الطلبة من أفكار وممارسات فكرية وقدرات قابلة للتطوير، واستخدامها كأسلوب تدريسي يختلف عن الطريقة الاعتيادية في تعليم وتعلم الرياضيات ويقوم على تعزيز ما يمتلكه الطلبة من عادات العقل، فإنها من الممكن أن تسهم في تطوير الكفاءة الرياضياة، وترغيب الطلبة بمبحث الرياضيات.

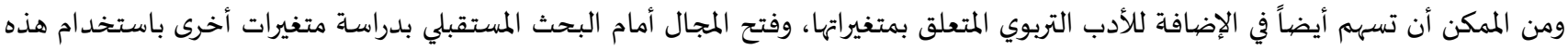

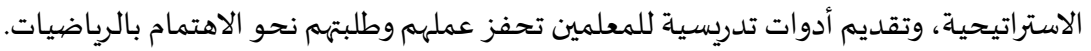

أما الأهمية التطبيقية: فمن المتوقع أن تسهم نتائج الدراسة الحالية في لفت انتباه واضعي السياسات والقرارات التربوية ومطوري المناهج الدراسية والباحثين والمعلمين إلى الأخذ بعين الاعتبار عادات العقل في تصميم وتطوير المناهج الدراسية وتضمين أنئ أدلة المعلمين التي تعمل على تعزيز وتمكين الطلبة من عادات العقل اللازمة لتدريس مبحث الرياضيات بما تحوياه من أنشطة ومهام تعليمية في مجال الرياضيات والمجالات الأخرى كذلك.

حدود الدراسة ومحدداتها: اقتصرت الدراسـة على الحدود والمحدددات الآتية:

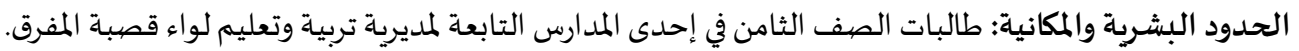

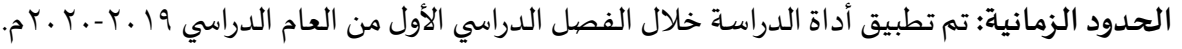

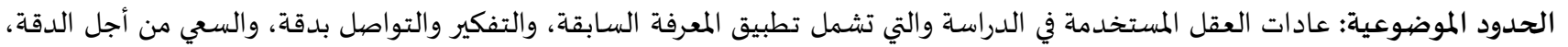
والمثابرة؛ لمناسبتها لأغراض الدراسة، وللتطبيق داخل الغرفة الصفية، وقد يكون لها ارتباط بأبعاد الكفاءة الرياضية المحددة في هذه الدراسة، بالإضافة

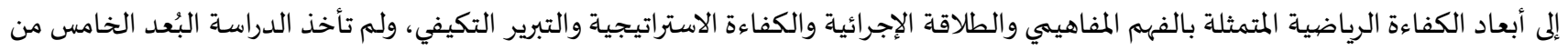
الكفاءة الرياضية وهو الميل المنتج نظراً لاختلاف ماهية هذا البُعد عن الأبعاد المختارة في هذه الدراسة والمتعلقة بالجانب المعرفي.

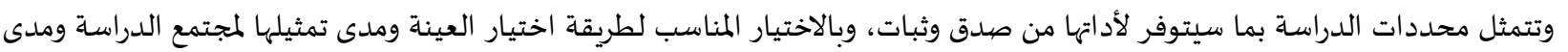

صدق استجابة أفراد عينة الدراسة على أداتها.

التعريفات الاصطلاحية والإجر ائية:

عادات العقل: القدرة على التصرف بذكاء عند مواجهة المشاكل، وعندما لا تكون الإجابات معروفة على الفور أو متاحة ضمن بنية الطالب المعرفية

(Costa \& Kallik, 2000) وتُعرف إجرائياً على أنها مجموعة من الممارسات الذهنية والسلوكيات التي تقوم بها الطالبة وتظهر من خلال أدائه للأنشطة والمهام الرياضية المقدمة لها أثناء تعلم وحدة الجبر في الرياضيات. الكفاءة الرياضية: المهارات الرياضية الواجب تطويرها في آنٍ واحد ليتمكن الطلبة من تعلم الرياضيات بنجاح، والمتمثلة بالفههم المفاهيمي والطلاقة الإجرائية والكفاءة الاستراتيجية والتبرير التكيفي والتصرف أرئه (الميل) المنتج (NRC, 2001).

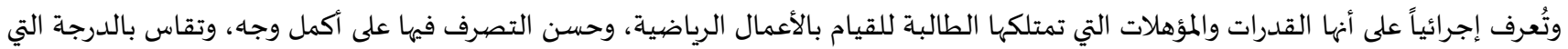
ستحصل عليها الطلبة على اختبار الكفاءة الرياضية. 
اتبع الباحثون في هذه الدراسـة المنهج الكمي (شبه التجريبي) ذا المجموعتين الضيابطة والتجريبية، وذلك لمناسبة هذا التصهيم لتحقيق هدف

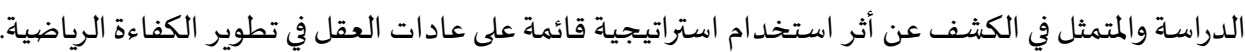

مجتمع الدراسـة:

تكون مجتمع الدراسة من جميع طالبات الصف الثامن الأساسي في مدارس وزارة التربية والتعليم التابعة لمديرية التربية والتعليم للواء قصببة

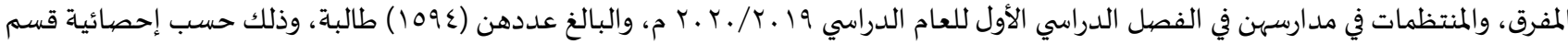
التخطيط في مديرية التربية والتعليم للواء قصبية المفرق. مداس عينة الدراسـة: تكونت عينة الدراسة من (V乏) طالبة من طالبات الصف الثامن الأساسي في مدرسة أم عطية الأنصارية التابعة لمديرية التربية والتعليم للواء

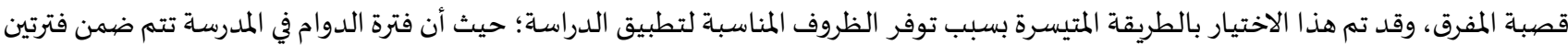

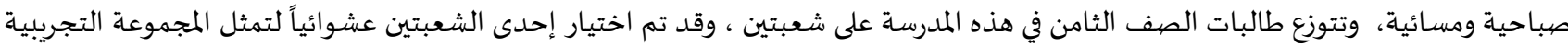

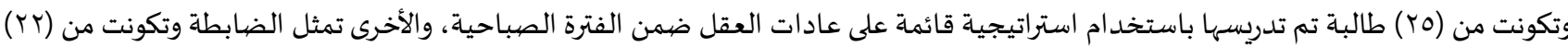

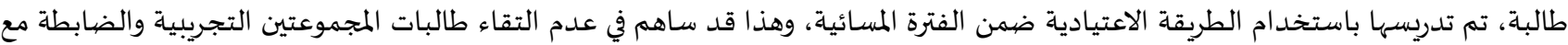
بعضهن البعض.

أدوات الدراسـة ومادتها التعليمية: لتحقيق أهداف الدراسة قام الباحثون بإعداد أدوات الدراسة وموادها التعليمية، وفيما يلي عرض لإجراءات إعداد كل أداة منها وطرق التحقق

من صددقها وثباتها:

المادة التعليمية، وتمثلت بما يأتي: دليل المعلم: لتحقيق هدف الدراسة الحالية تم إعداد دليل المعلم لاستخدام استراتيجية تدريسية قائمة على عادات العقل، وذلك بعد الاطلاع على

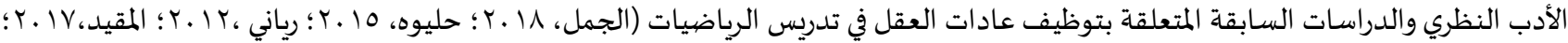
Costa \& Kallick, 2000, 2009; Kallick \& Zmuda, 2017 الثامن الأساسي، وعليه تمت إعادة صياغة وحدة الجبر وفقاً لاستراتيجية تدريسية قائمة على عادات العقل، وتضهمن الدليل ما يأتي: الإطار النظري: ويتضمن مقدمة ولمحة عامة عن عادات العقل وتوظيفها في تدريس الرياضيات. الإطار الإجرائي: ويتضمن إجراءات تنفيذ دروس وحدة الجبر باستخدام عادات العقل، من حيث أسلوب التدريس حسب الاستراتيجية القائمة على

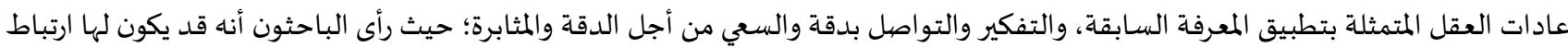
بأبعاد الكفاءة الرياضياة، وأنها ملائمة للتطبيق داخل الغرفة الصفية ، ثم تحديد المواد التعليمية ووسائل الشرح اللازمة، وتقديم الأسئلة والأنشطة

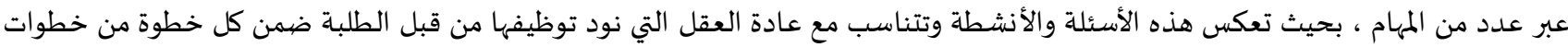
الاستراتيجياة، من خلال تقديم أوراق العمل للمجموعات المتعاونة بداية كل حصة دراسية، ثم الطلب من الطلبة القيام بتنفيذ الواجب البيتي المتعلق بكل درس، بالإضافة إلى أن الدليل يتضمن الخطة الزمنية المقترحة لتطبيق دروس وحدة الجبر، مع التقيد بالدروس المقررة ضمن منهم منهاج وزارة التربية

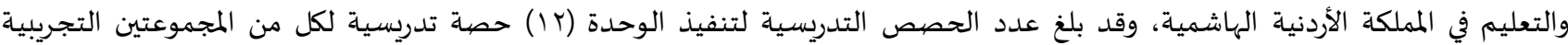
والضيابطة. دليل الطالب: تم إعداد دليل الطالب المتضمن للتعريف بوحدة الجبر، وإرشادات تنفيذ أنشطة التعلم، وعبارات لدعم الطالب نحو التعلم ولتوظيف

عادات العقل، وأوراق العمل المتعلقة بكل درس من دروس وحدة الجبر، والتي يقوم الطالب بتنفيذها ضيمن المجموعات التعاونية.

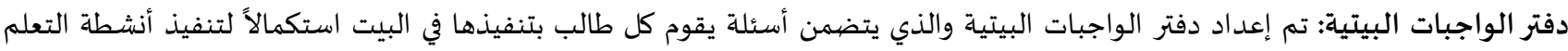
المتعلقة بعادات العقل؛ ليقوم الطالب بالاعتماد على نفسـه وممارسة عادات العقل، في ظل ما نراه من حلول مقدمة وجاهزة ومتاحة بين أيدي الطلبة

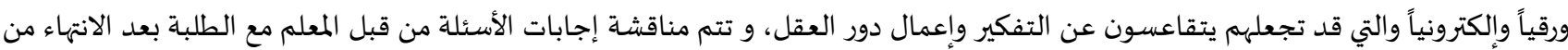
تنفيذها، وتصحيح الأخطاء لديهم إن وجدت، وانتهى بتقييم ذاتي للطلبة للحكم على مدى التزامهم بتنفيذ المهام والواجبات الموكلة إليهم.

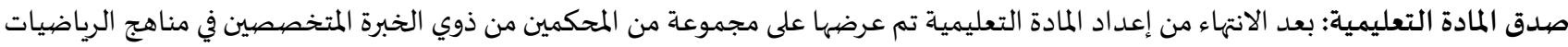
وأسـاليب تدريسها، ومشرفي ومعلمي الرياضيات ذوي الخبرة؛ لإبداء آرائهم وملاحظاتهم حول محتواها، حيث طلب إلى كل منهم إبداء رأيه من حيث سلامة الصياغة اللغوية للنتاجات التعلمية ووضوحها ودقتها وشمولها لمحتوى وحدة الجبر، وسلامة الصياغة اللغوية والدقة العلمية واللغوية في صياغة 
أنشطة كل درس، وقابليها للتنفيذ، وتوزيع وقت إجراءات الحصص التدريسية، وتخطيط الدروس حسب عادات العقل، وملاءمة المادة التعليمية

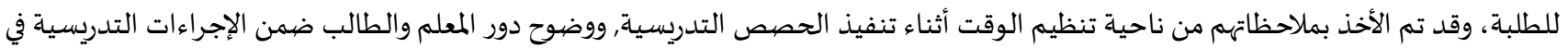

اختبار الكفاءة الرياضية: بهدف الكشف عن الكفاءة الرياضية لدى طالبات الصف الثامن الأساسي، قام الباحثون بإعداد اختبار الكفاءة الرياضية

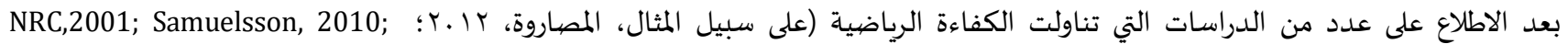

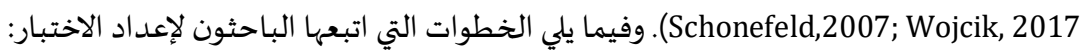

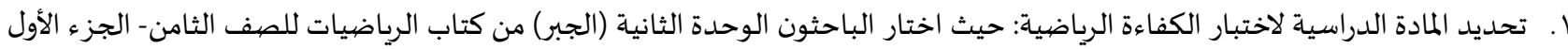

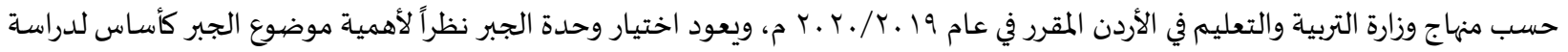
الرياضيات، وملاءمة محتوى وحدة الجبر لأهد اف الدراسة الحالية.

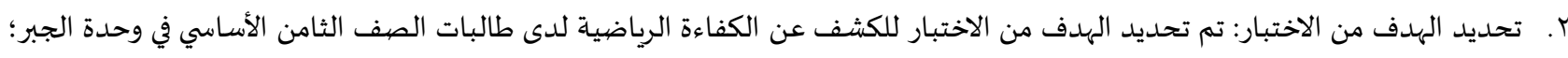

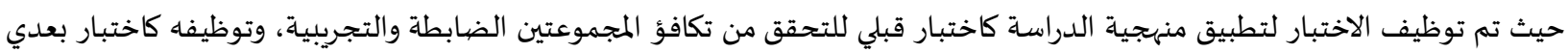
للكشف عن أثر استخدام استراتيجية تدريسية قائمة على عادات العقل في تطوير الكفاءة الرياضية لدى طالبات المجموعتين الضابطة تهنية

r. تحليل محتوى وحدة الجبر وفقاً لأبعاد الكفاءة الرياضية (الفهم المفاهيمي، والطلاقة الإجرائية، والطلاقة الاستراتيجية، والتبرير التكيفي). ع. إعداد جدول المواصفات وفقاً لأبعاد الكفاءة الرياضية.

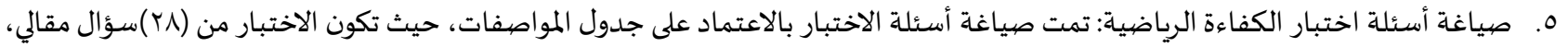

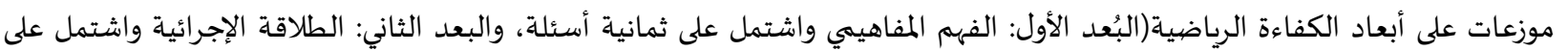

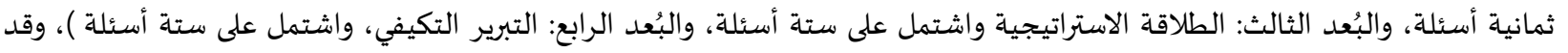
بلغت العلامة الكلية للاختبار (70) علامة، مع مراعاة الدقة العلمية واللغوية للأسئلة، ووضيوحها.

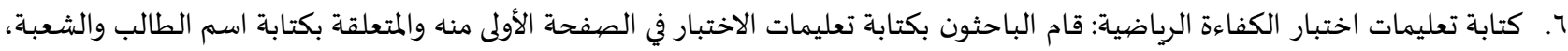

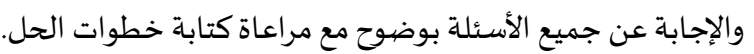

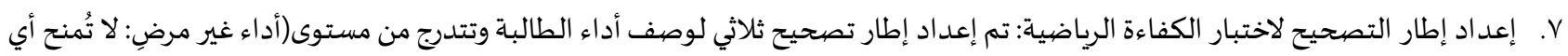

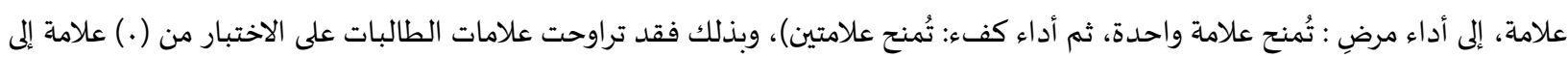
(07) علامة. ^. التحقق من صدق اختبار الكفاءة الرياضية: للتحقق من الصدق الظاهري وذلك من خلال عرض أسئلة الاختبار بصيورته الأولية على عدد من

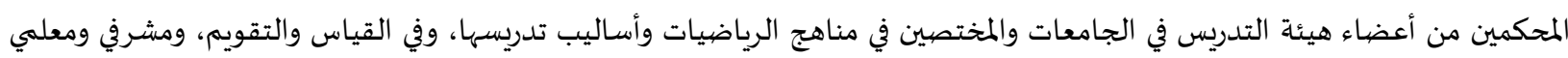

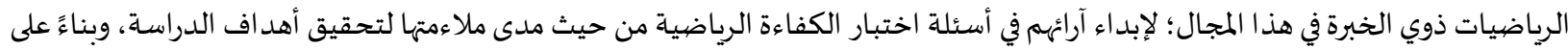

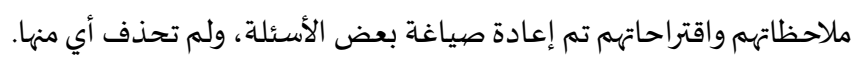

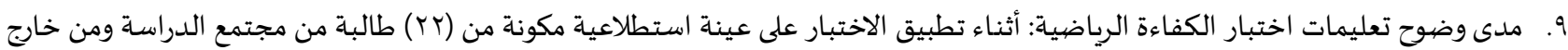

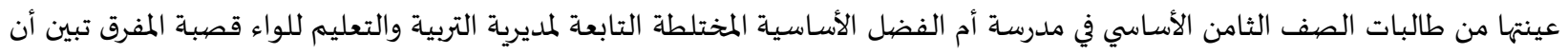
تعليمات الاختبار واضحة، ولم تسأل أي طالبة سؤالاً يتعلق بصياغة الأسئلة.

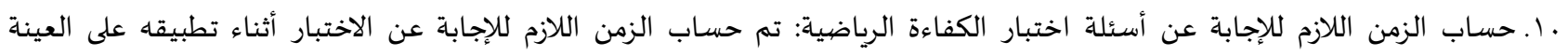

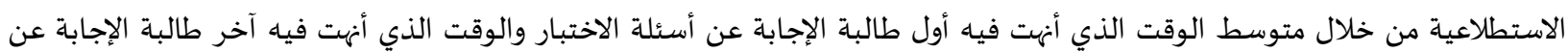
أسئلة الاختبار كما يأتي:

(الوقت الذي أنهت فيه أول طالبة الإجابة عن أسئلة الاختبار +الوقت الذي أهت فيه آخرطالبة الإجابة عن أسئلة الاختبار)/Y) =

$$
\text { . }
$$

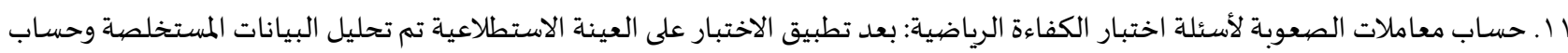

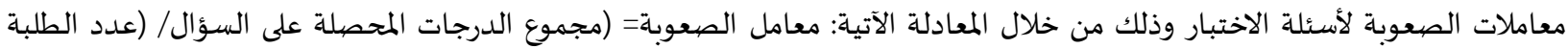

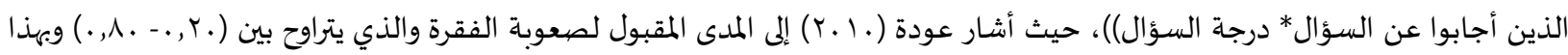

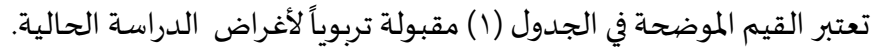


جدول (1): معاملات الصعوبة لأسئلة اختبار الكفاءة الرياضياة

\begin{tabular}{|c|c|c|c|c|c|c|c|}
\hline معامل الصعوبة & رقم السؤال & معامل الصعوبة & رقم السؤال & معامل الصعوبة & رقم السؤال & معامل الصعوبة & رقم السؤال \\
\hline .01 & rr &., $0 \mathrm{~V}$ & 10 &., $0 \leqslant$ & 1 &., 07 & 1 \\
\hline · TV & rr &., 07 & 17 &., 01 & 9 & . & r \\
\hline 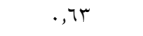 & $r \varepsilon$ & . $\mathrm{VO}_{\mathrm{O}}$ & iv & ., $\mathrm{r}$. & 1. & . , vo & $r$ \\
\hline . TV & ro & . v. & is &., 01 & 11 & זור, & $\varepsilon$ \\
\hline r זר, & r & זד, & 19 & -, vo & ir & ., Vo & 0 \\
\hline . VY & tr &., 0 & r. & 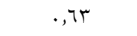 & ir &., 00 & 7 \\
\hline$\cdot, 01$ & ५ & ., 0. & $r$ &., 01 & $1 \varepsilon$ & . 7 . & v \\
\hline
\end{tabular}

r ا . حساب معاملات التمييز لأسئلة اختبار الكفاءة الرياضياة: لحساب معامل التمييز تم تقسيم العينة الاستطلاعية إلى مجموعتين عليا ودنيا بحيث تمثل المجموعة العليا الطلبة الذين حصلوا على الدرجات المرتفعة، والمجموعة الدنيا تضم الطلبة الذين حصلوا على الدرجات المتدنية، بنسبة

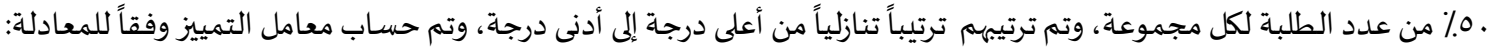

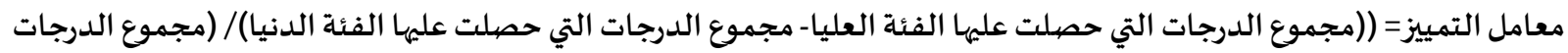
المخصصية للسؤال*عدد الطلبة في إحدى المجموعتين)).

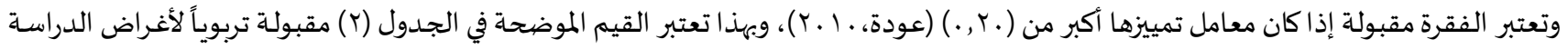
الحالية.

جدول (Y): معاملات التمييز لأسئلة اختبار الكفاءة الرياضية

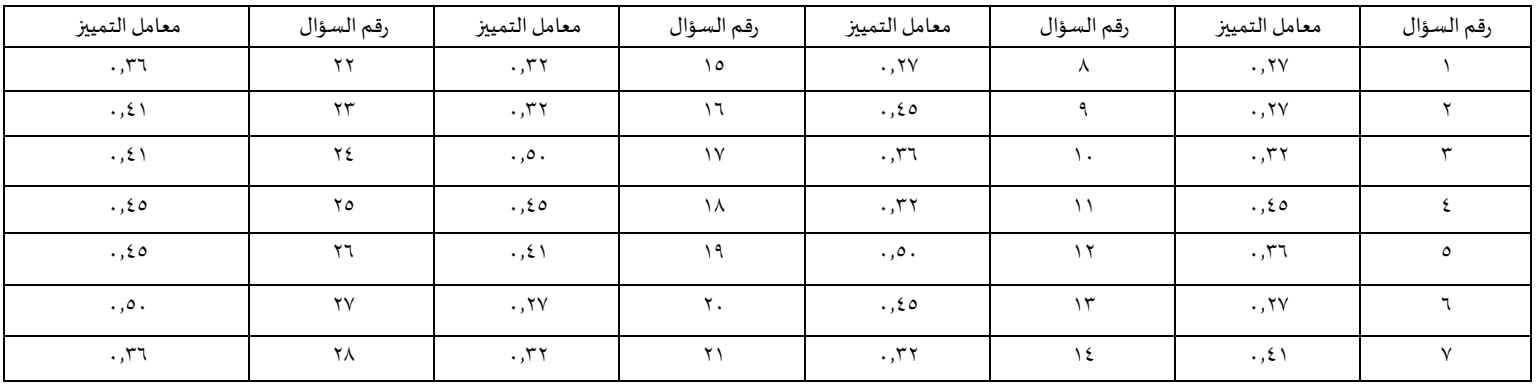

rا ـ التحقق من صدق الاتساق الداخلي لاختبار الكفاءة الرياضية وذلك باستخدام معامل ارتباط بيرسون من خلال إيجاد معامل ارتباط كل سؤال مع بُعد الكفاءة الرياضية الذي ينتمي إليه، وحساب معامل ارتباط كل بُعد من أبعاد الكفاءة الرياضية مع الاختبار ككل، كما هو موضح في جدول

جدول (r): معامل الارتباط بين كل سؤال من أسئلة أبعاد الكفاءة الرياضية والعلامة الكلية للبُعد، ومعامل الارتباط بين علامة كل بُعد من أبعاد الكفاءة الرياضية ومعامل الارتباط الكلي للاختبار

\begin{tabular}{|c|c|c|c|c|c|}
\hline معامل ارتباط بيرسون & معامل ارتباط بيرسون & رقم السؤال & معامل ارتباط بيرسون & رقم السؤال & أبعاد الكفاءة الرياضية \\
\hline \multirow[t]{4}{*}{ 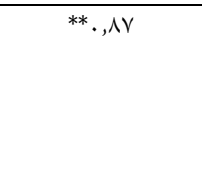 } & **., $\Sigma 7$ & $\circ$ & ${ }^{* *} \cdot, \mathrm{V} \varepsilon$ & 1 & \multirow{4}{*}{ البُمفاهيهي الأول: الفهم } \\
\hline & $*_{., \text {Or }}$ & 7 & **., 07 & $r$ & \\
\hline & **., 70 & v & $*, 0$ & $r$ & \\
\hline & $* * ., V V$ & $\wedge$ & $*_{., 01}$ & $\varepsilon$ & \\
\hline \multirow[t]{4}{*}{ **., qr } & **., V7 & 14 & $*_{., \text {or }}$ & 9 & \multirow{4}{*}{ الإجبرائية الثاني: الطلاقة } \\
\hline & **., $\vee$. & $1 \varepsilon$ & $* * ., 1 \curlywedge$ & 1. & \\
\hline & **., १ו & 10 & **., 79 & 11 & \\
\hline & $* * ., 79$ & 17 & **., 77 & Ir & \\
\hline \multirow[t]{3}{*}{$* * ., 9 \varepsilon$} & **., V7 & r. & **.,09 & IV & \multirow{3}{*}{ الاستبراتيجية الثالث: الطلاقة } \\
\hline & $* * ., 01$ & rI & ${ }^{* *} ., V T$ & 11 & \\
\hline & **.,, . & rr & **., 09 & 19 & \\
\hline \multirow[t]{3}{*}{ **.,90 } & **., $\mathrm{\vee \wedge}$ & r & **., 77 & $r$ & \multirow{3}{*}{ التكيفيف الرابع: التبرير } \\
\hline & **., $\mathrm{VA}$ & TV & $* * ., 79$ & $r \varepsilon$ & \\
\hline & $* * ., 01$ & $r \wedge$ & ${ }^{* *} ., 0 \leqslant$ & ro & \\
\hline
\end{tabular}


يبين الجدول (r) أن أسئلة اختبار الكفاءة الرياضية ذات دلالة إحصائية، وهذا يشير إلى أن الأسئلة متسقة داخلياً، وأن معامل الارتباط بين

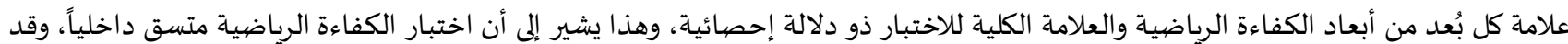

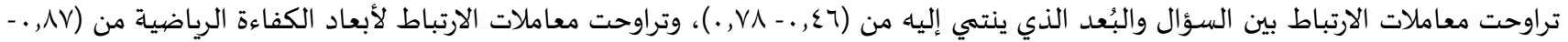

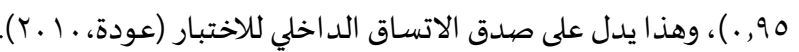

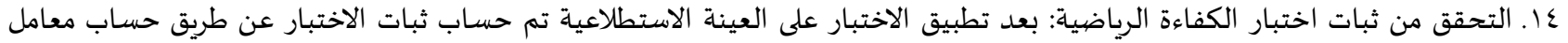

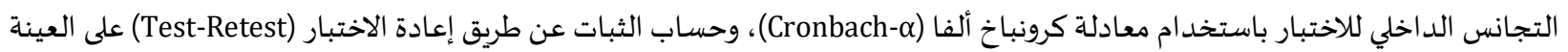
الاستطلاعية بفاصل زمني مقداره أسبوعان بين التطبيق الأول والتطبيق الثاني باستخدام معامل ارتباط بيرسون، وحساب قيات التانيم الثبات لأبعاد

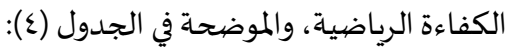

جدول (ع): معامل ثبات التجانس الداخلي وثبات الإعادة لاختبار الكفاءة الرياضية

\begin{tabular}{|c|c|c|c|}
\hline ثبات الإعادة & التجانس الداخلي & عدد الأسئلة & أبعاد الكفاءة الرياضية \\
\hline **., ^乏 & . $\mathrm{Vr}$ & 1 & الفهم المفاهيمي \\
\hline **., 94 & • Ar & 1 & الطلاقة الإجرائية \\
\hline **.,, 91 & $\cdot, \mathrm{Vr}$ & 7 & الطلاقة الاستراتيجية \\
\hline${ }^{* *}$, , ^ & ., Vo & 7 & التبرير التكيفي \\
\hline${ }^{* *} ., 9 \varepsilon$ & rar & ru & الاختبار الكلي \\
\hline
\end{tabular}

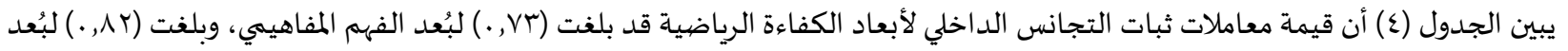

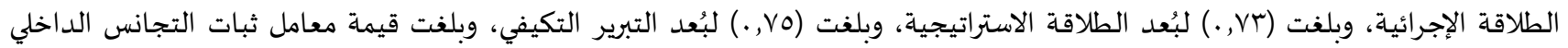

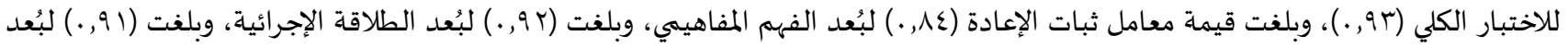

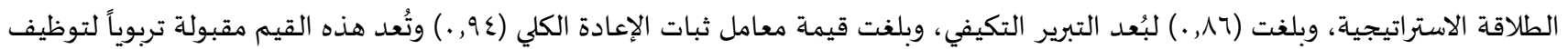

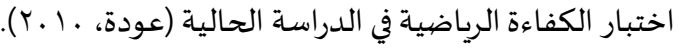

إجراء اختبار التوزيع الطبيعي (Normality): تم التأكد من إتباع البيانات التوزيع الطبيعي (Normal Distribution) باستخدام اختبار (Oتئبار (One Sample Kolmogorov-Smirnov test)، والجدول (0) يبين ذلك.

جدول(0): اختبار (One Sample Kolmogorov-Smirnov test) لاختبار الكفاءة الرياضية

\begin{tabular}{|c|c|c|}
\hline الإحصائية & 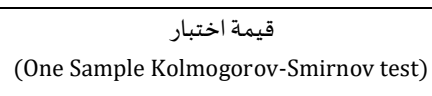 & المتغير \\
\hline$\ldots .19$ & $1, T V I$ & الفهم المفاهيهي قبلي \\
\hline., 1 To & $1,1 \mathrm{VV}$ & الطلاقة الإجرائية قبلي \\
\hline., 1.9 & I,Y.V & الطلاقة الاستراتيجية قبلي \\
\hline., $1 \leqslant 9$ & $1,1 \varepsilon$. & التبرير التكيفي قبلي \\
\hline$\cdot, \varepsilon \vee \wedge$ & $\cdot, \Lambda \leqslant Y$ & اختبار الكفاءة الرياضية قبلي \\
\hline., $10 \mathrm{~V}$ & $1,1 \mathrm{TV}$ & الفهم المفاهيمي بعدي \\
\hline . & .,TKY & الطلاقة الإجرائية بعدي \\
\hline., $1 T_{0}$ & $1,1 \vee \wedge$ & الطلاقة الاستراتيجية بعدي \\
\hline., 9 & $1, r \leqslant 7$ & التبرير التكيفي بعدي \\
\hline., 770 &.,$V Y A$ & اختبار الكفاءة الرياضية بعدي \\
\hline
\end{tabular}

يتبين من الجدول رقم (0) أن قيمة الدلالة الإحصائية لاختبار (One Sample Kolmogorov-Smirnov test) لاختبار الكفاءة الرياضية ولجميع

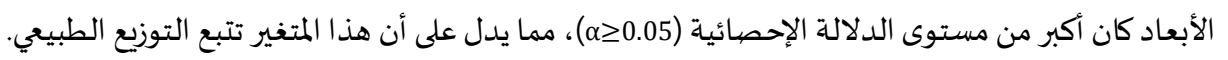

التحقق من تكافؤ المجموعتين الضيابطة والتجريبية: للتحقق من تكافؤ المجموعتين الضابطة والتجريبية قبل البداء بتطبيق التجربة تم تطبيق اختبار الكفاءة الرياضية على المجموعتين وذلكابلك من

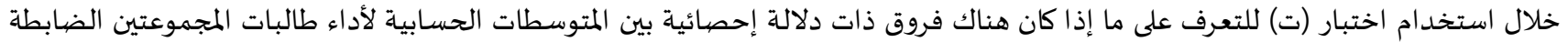

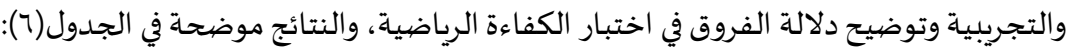


جدول(7): نتائج اختبار(ت) للبيانات المستقلة للمقارنة بين متوسط علامات الطالبات في المجموعة التجريبية ومتوسط علامات الطالبات في المجموعة

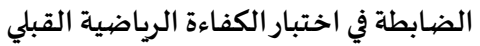

\begin{tabular}{|c|c|c|c|c|c|c|c|}
\hline الدلالة الإحصبائية & قيمة(ت) & درجات الحرية & الانحراف المعياري & المستوسط الحسبي & العدد & المجموعة & أبعاد الكفاءة \\
\hline \multirow[t]{2}{*}{ - } & .,r.r & 纟o & $1, r \wedge \varepsilon$ & $r, \ldots$ & ro & التجريبية & \multirow[t]{2}{*}{ الفهم المفاهيمي } \\
\hline & & & 1,799 & 1,17 & rr & الضابطة & \\
\hline \multirow[t]{2}{*}{., $1 \times 9$} & $1,0 \leqslant 0$ & 纟o & $r, 1 . \varepsilon$ & r,Or & ro & التجريبية & \multirow[t]{2}{*}{ الطلاقة الإجرائية } \\
\hline & & & $1, r \leqslant r$ & $1, \mathrm{Vr}$ & rr & الضابطة & \\
\hline \multirow[t]{2}{*}{., $0 \mathrm{VI}$} &., $0 \mathrm{~V}$. & 纟o & $1,1 v 9$ & 1,17 & ro & التجريبية & \multirow[t]{2}{*}{ الطلاقة الاستراتيجية } \\
\hline & & & $1, r 9$. &., 90 & rt & الضيطة & \\
\hline \multirow[t]{2}{*}{. } & ., $\mathrm{V} / \mathrm{T}$ & 纟o & $1, . r$. & $1, . \varepsilon$ & ro & التجريبية & \multirow[t]{2}{*}{ التبرير التكيفي } \\
\hline & & & I,.rr & $1, r V$ & r & الضيابطة & \\
\hline \multirow[t]{2}{*}{$\cdot,\{\wedge 9$} &., 791 & 纟o & $\varepsilon, 7 \leqslant 1$ & $7, V T$ & ro & التجريبية & \multirow[t]{2}{*}{ 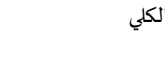 } \\
\hline & & & $\varepsilon, 1 \leqslant \lambda$ & $0, \Lambda Y$ & Tr & الضابطة & \\
\hline
\end{tabular}

ويتبين من الجدول (7) أن قيمة (ت) المحسوبة غير دالة إحصائياً عند مستوى الدلالة (1) (م) )، وهذا يشير إلى عدم وجود فرق ذي دلالة إحصائية بين متوسط علامات الطالبات في المجموعة التجريبية ومتوسط علامات الطالبات في المجموعة الضابطة في اختبار الكفاءة الرياضية القبلي، وهذا يدل على تكافؤ مجموعات الدراسة. إجراءات تنفيذ الدراسة تحديد مشكلة الدراسـة. الاطلاع على الأدب النظري والدراسات السابقة المتعلقة بمتغيرات الدراسة. تحديد وحدة الجبر من كتاب الرياضيات للصف الثامن وإعادة صياغتها باستخدام الاستراتيجية القائمة على عادات العقل وتدريسها للمجموعة

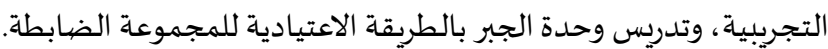
إعداد أدوات الدراسة بصورتها الأولية، ثم التحقق من صدقها وثباتها لتصبح في صورتها النهائية. اختيار عينة الدراسة وتقسيمها عشوائياً إلى مجموعتين إحداهما تجريبية والأخرى ضابطة. تطبيق اختبار الكفاءة الرياضياة على العينة الاستطلاعية ثم إعادة تطبيقه على العينة ذاتها بعد أسبوعين للتحقق من صدقه وثباته، وتحديد زمن الاختبار.

اللقاء مع معلمة الرياضيات لتعريفها بكيفية تدريس وحدة الجبر باستخدام عادات العقل لطالبات المجموعة التجريبية، بهدف تعريفها بكيفية

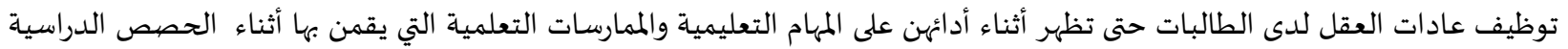

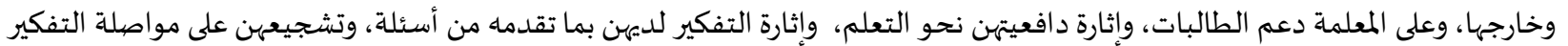

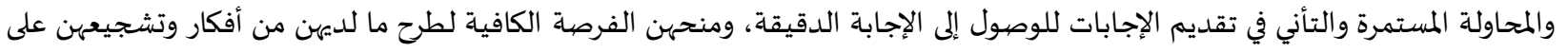
تبادلها فيما بينهن، وتوضيح طرق الوصول إليها، ومساعدتهن على تجاوز ما يواجهن من صيعوبات لكن دون إعطاء الإجابات لهن ،وضبط مجئ مجريات

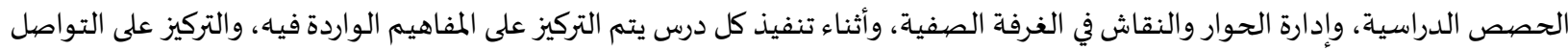

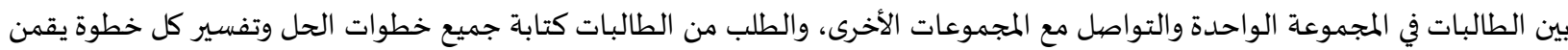

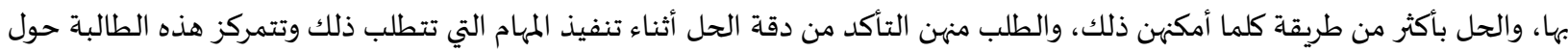

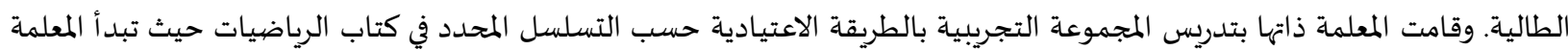
بكتابة اسم الدرس في بداية كل حصة وتقديم مجموعة من الأمثلة المتعلقة بموضوع الدرس، ثم تقويم أداء الطالبات من خلال التدريبات الموجودة في الكتاب، ثم تعيين بعض الأسئلة من تمارين ومسائل كواجب بيتي في نهاية كل حصنة وتئ وتتمركز هذه الطريقة حول المعلمة. لقاء المعلمة مع طالبات المجموعة التجريبية من أجل تعريفهن بالاستراتيجية التدريسية القائمة على عادات العقل وما عليهن من إجراءات تتطلب مححاولة استعادة المعارف السـابقة لديهن عن الموضوع المراد تعلماه، وطرح الأسئلة التي تلبي احتياجاتهن التعلمية، وممارسة التفكير وطرح الأفكار

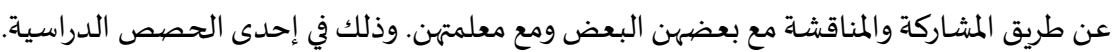
إجراء التطبيق القبلي لاختبار الكفاءة الرياضية على المجموعتين التجريبية والضابطة للتحقق من تكافؤ المجموعتين التجريبية والضابطة، وذلك 
البدء بتدريس وحدة الجبر باستخدام عادات العقل لطالبات المجموعة التجريبية وتدريسها لطالبات المجموعة الضابطة بالطريقة الاعتيادية بواقع (r ا ) حصة لكل من المجموعتين التجريبية والضابطة. • إجراء التطبيق البعدي لاختبار الكفاءة الرياضية على المجموعتين التجريبية والضابطة، وذلك بعد تنفيذ الدراسة وتصحيحهـ. تحليل البيانات ومعالجتها باستخدام برنامج الرزم الإحصائية (SPSS) واستخلاص النتائج ومناقشتها وذلك للإجابة عن سؤال الدراسة واختبار فرضيتها. متغيرات الدراسـة: المتغيرات المستقلة:

طريقة التدريس ولها مستويان: الاستراتيجية التدريسية القائمة على عادات العقل.

الطريقة الاعتيادية.

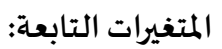

الكفاءة الرياضية.

تصيميم الدراسة: - n

تم استخدام التصميم شباه التجريبي لمجموعتين (تجريبية وضابطة) كما يأتي: $\begin{array}{llll}\text { المجموعة التجريبية } & \mathrm{O}_{1} & \mathrm{X} & \mathrm{O}_{1}\end{array}$ المجموعة الضيطابطة حيث أن: 1 X المعالجة التجريبية (الاستراتيجية التدريسية). _ : ب الطريقة الاعتيادية.

المعالجة الإحصيائية: تم استخدام البرنامج الإحصائي للعلوم الاجتماعية (SPSS)، واختبار (t-test) للبيانات المستقلة، وحساب المتوسطات الحسابية، والانحرافات

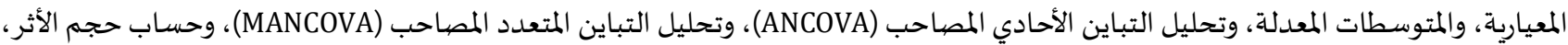
للإجابة عن سؤال الدراسة.

\section{نتائج الدراسـة:}

النتائج المتعلقة بسؤال الدراسـة: ما أثر استخدام استر اتيجية تدريسية قائمة على عادات العقل في تطوير الكفاءة الرياضية لدى طلبة الصف الثامن الأساسي؟ وانبثق عن السؤال الأول الفرضية الصفرية الآتية: " لا يوجد فرق ذو دلالة إحصائية بين متوسط علامات الطالبات في المجموعة التجريبية ( اللواتي درسن باستخدام استراتيجية قائمة على عادات العقل" ومتوسط علامات الطالبات في المجموعة الضابطة (اللواتي درسن باستخدام الطريقة الاعتيادية) في اختبار الكفاءة الرياضية البعدي". للتحقق من صحة الفرضية تم حساب المتوسطات الحسابية والانحرافات المعيارية للتطبيقين القبلي والبعدي على اختبار الكفاءة الرياضية، وكانت النتائج كما هو موضح في هندي الجدول(V).

جدول(V): المتوسطات الحسابية والانحر افات المعيارية لاختبار الكفاءة الرياضية للقياسين القبلي والبعدي تبعاً للمجمموعة (تجريبية- ضابطة)

\begin{tabular}{|c|c|c|c|c|c|}
\hline \multicolumn{2}{|c|}{ القياس البعدي } & \multicolumn{2}{|c|}{ القياس القبلي } & & \\
\hline الانحراف المعياري & المتوسط الحسابي & الانحراف المعياري & المتوسط الحسابي & العدد & المجموعة \\
\hline$\Lambda, Y, \varepsilon$ & $19, \Gamma Y$ & $\varepsilon, 7 \varepsilon 1$ & $7, V Y$ & ro & تجريبية \\
\hline 0, rit & $9,1 \varepsilon$ & $\varepsilon, 1 \varepsilon \wedge$ & $0, \lambda Y$ & rr & ضابطة \\
\hline
\end{tabular}


يلاحظ من الجدول(V) وجود فروق بين متوسط علامات الطالبات في المجموعتين التجريبية و الضابطة في اختبار الكفاءة الرياضية في القياسين القبلي والبعدي تبعاً للمجموعة (تجريبية ، ضيابطة)، ولمعرفة فيما إذا كانت هذه الفروق ذات ذات دلالة إحصائية تم استخدام تحليل التباين الأحادي المصاحب (One way ANCOVA) للقياس البعدي لاختبار الكفاءة الرياضية تبعاً للمجموعة (تجريبية، ضابطة) بعد تحييد أثر القياس القبلي لديهن،

$$
\text { والجدول(^) يوضح ذلك: }
$$

جدول (^): نتائج تحليل التباين الأحادي المصاحب (One way ANCOVA) للقياس البعدي ككل تبعاً للمجموعة (تجريبية، ضابطة) بعد تحييد أثر القياس القبلي

\begin{tabular}{|c|c|c|c|c|c|c|}
\hline 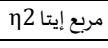 & مستوى الدلالة & قيمة ف & متوسط مجموع المربعات & درجات الحرية & مجموع المربعات & مصدر التباين \\
\hline & $\ldots$ & $r \Lambda, . \nu \gamma$ & $1.1 \varepsilon, 1 \times 9$ & 1 & $1.1 \varepsilon, 1 \times q$ & القياس القبلي \\
\hline \multirow[t]{3}{*}{ 作, 207} & 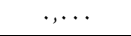 & $r 7,9.7$ & $9 \wedge r, 97 \%$ & 1 & $9 \wedge r, 97 r$ & المجموعة لمجة \\
\hline & & & (T, \& & $\varepsilon \varepsilon$ & $11 V 1, \Delta 95$ & الخطأ \\
\hline & & & & $\varepsilon 7$ & $r+99,71 \mathrm{~V}$ & الكلي \\
\hline
\end{tabular}

يتضح من الجدول (^) وجود فروق ذات دلالة إحصائية عند مستوى دلالة (a=0.05) في درجات الطالبات في اختبار الكفاءة الرياضية وفقاً

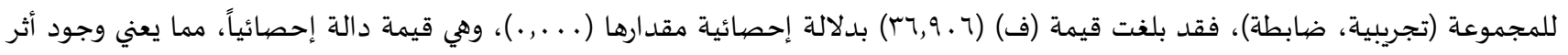
للمجموعة.

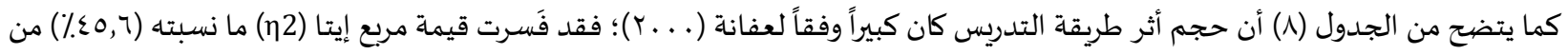

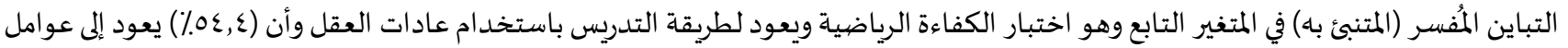
أخرى غير متحكم بها. ولتحديد لصالح أي من مجموعتي الدراسـة تعزى الفروق، تم حساب المتوسطات الحسابية المعدلة والأخطاء المعيارية لها وفقا للمجموعة، وذلك مئك

كما هو مبين في الجدول (9).

جدول (9): المتوسطات الحسابية المعدلة والأخطاء المعيارية لها لاختبار الكفاءة الرياضية تبعاً للمجموعة (تجريبية، ضابطة)

\begin{tabular}{|c|c|c|}
\hline الخطأ المعياري & المتوسط الحسابي البعدي الممعدل & المجموعة 20 كموة \\
\hline $1, .50$ & 11,177 & تجريبية \\
\hline $1,1 . r$ & $9,70 \mathrm{r}$ & ضابطة \\
\hline
\end{tabular}

تشير النتائج في الجدول (9) إلى أنّ الفروق كانت لصالح المجموعة التجريبية التي تعرضت لاستراتيجية تدريسية قائمة على عادات العقل مقارنة بأفراد المجموعة الضابطة.

كما تم حساب المتوسطات الحسابية والانحرافات المعيارية للقياسين القبلي والبعدي لأبعاد اختبار الكفاءة الرياضية وفقاً للمجموعة (تجريبية، ضابطة)، كما هو مبين في الجدول (. (1). جدول ( • (): المتوسطات الحسابية والانحر افات المعيارية للقياسين القبلي والبعدي لأبعاد اختبار الكفاءة الرياضية وفقاً للمجموعة

\begin{tabular}{|c|c|c|c|c|c|c|}
\hline \multicolumn{2}{|c|}{ القياس البعدي } & \multicolumn{2}{|c|}{ القياس القبلي } & \multirow{2}{*}{ 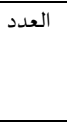 } & \multirow{2}{*}{ 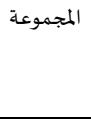 } & \multirow[t]{2}{*}{ الأبعاد } \\
\hline الانحراف المعياري & لحسابي المتوسط & الانحراف المعياري & المتوسط الحسابي & & & \\
\hline r, rNv & 7,17 & $1, r \wedge \varepsilon$ & $r, \ldots$ & ro & تجريبية & \multirow[t]{2}{*}{ الفهم المفاهيهي بعدي } \\
\hline$r, Y 90$ & $r, 1 \varepsilon$ & 1,799 & 1,17 & rr & ضابطة & \\
\hline r, Yos & 7,07 & $r, 1 . \varepsilon$ & T,OT & ro & تجريبية & \multirow[t]{2}{*}{ الطلاقة الإجرائية بعدي } \\
\hline$r, 1 \leqslant V$ & r,rer & $1, r \leqslant 1$ & $1, V r$ & rr & ضابطة & \\
\hline $1,9 r \varepsilon$ & $r, T \varepsilon$ & $1,1 \vee 9$ & 1,17 & ro & تجريبية & \multirow[t]{2}{*}{ الطلاقة الاستراتيجية بعدي } \\
\hline $1, . \wedge r$ & $1,1 \varepsilon$ & $1, r q$ &., 90 & rr & ضابطة & \\
\hline$r, \varepsilon Y r$ & $r, 97$ & $1, \cdot r$. & $1, . \varepsilon$ & ro & تجريبية & \multirow[t]{2}{*}{ التبرير التكيفي بعدي } \\
\hline$r, . I V$ & 1,00 & 1,.rr & $1, r V$ & rr & ضابطة & \\
\hline
\end{tabular}

يلاحظ من الجدول (. ا) وجود فروق ظاهرية بين المتوسطات الحسابية في القياسين القبلي والبعدي لأبعاد اختبار الكفاءة الرياضية ناتج عن اختلاف المجموعة (تجريبية، ضابطة)، وبهدف التحقق من جوهرية الفروق الظاهرية، تم تطبيق تحليل التباين المصاحب الأحادي المتعدد (One way)

MANCOVA) 
جدول (11): نتائج تحليل التباين الأحادي المصاحب المتعدد لأثر المجموعة (تجريبية، ضابطة)على أبعاد اختبار الكفاءة الرياضية

\begin{tabular}{|c|c|c|c|c|c|c|c|}
\hline حجم الأثر & احتمالية الخطأ & درجة حرية & درجة حرية & فـ الكلية & قيمة الاختبار & نوع الاختبار المتعدد & الأثر \\
\hline 位 &.,$\ldots$ & $r \wedge, \ldots$ & $\varepsilon, \ldots$ & $V, Y 74$ & ., V7o & Hotelling's Trace & طريقة التدريس \\
\hline
\end{tabular}

يتبين من الجدول (1) وجود أثر لطريقة التدريس ذو دلالة إحصائية عند مستوى الدلالة (0. . .) على القياس البعدي لأبعاد اختبار الكفاءة

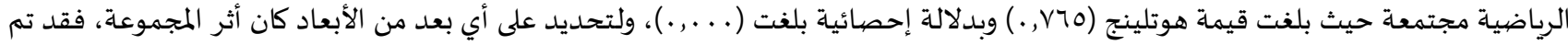
إجراء تحليل التباين الاحادي المصاحب (ANCOVA) لكل بعد على حدة وفقاً للمجموعة بعد تحييد أثر القياس القبلي لديهم، وذلك كما هو مبين في إئل

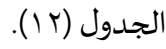

جدول (r (): تحليل التباين الأحادي المصاحب (ANCOVA) لأثر المجموعة على القياس البعدي لكل بعد من أبعاد اختبار الكفاءة الرياضية بعد تحييد أثر القياس

\begin{tabular}{|c|c|c|c|c|c|c|c|}
\hline \multicolumn{8}{|c|}{ القبلي } \\
\hline حجم الأثر & مستوى الدلالة & ف ف & وسط مجموع المربعات & درجة الحرية & مجموع المربعات & & مصدر التباين \\
\hline & - 999 & $\cdot, \ldots$ & ., $\ldots$ & 1 &,$\ldots$ & الفهم المفاهيمي بعدي & $\begin{array}{r}\text { (الفهم المفاهيهي القبلي } \\
\text { (المصاحب) }\end{array}$ \\
\hline & (IT & $1, . \Sigma 9$ & $0,1 v$. & 1 & $0,1 \mathrm{r}$. & الطلاقة الإجرائية بعدي & (المصاحب) الإجرائية القبلي \\
\hline & .941 &,$\ldots 1$. &., 19 & 1 &., .19. & الطلاقة الاستراتيجية بعدي & 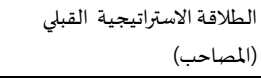 \\
\hline & 正, & $1, \varepsilon \varepsilon V$ & $0, \mathrm{YVY}$ & 1 & $0, \mathrm{TYY}$ & التبرير التكيفي بعدي & التبرير التكيفي القبلي (المصاحب) \\
\hline ., $10 \leqslant$ & $\ldots 9$ & $r, \varepsilon 09$ & $0 r, \Lambda \cdot \Lambda$ & 1 & $0 r, \lambda \cdot A$ & الفهم المفاهيهي بعدي & المجموعة \\
\hline . rTA & , , . & 19,994 & $9 \wedge, 0 \mathrm{rr}$ & 1 & $9 \wedge, 0 \mathrm{Tr}$ & الطلاقة الإجرائية بعدي & \\
\hline ., Ir &., 19 & $0,9 \mathrm{TV}$ & $11, r q$. & 1 & $11, r 9$. & الطلاقة الاستراتيجية بعدي & \\
\hline . 111 & $\ldots \varepsilon$ & $9, .0$. & $r, \ldots q$ & 1 & $\pi, \ldots 9$ & التبرير التكيفي بعدي & \\
\hline & & & $\gamma, \cdot \Lambda$. & «) & $r q ., T V \varepsilon$ & الفهم المفاهيهي بعدي & الخطأ \\
\hline & & & $\varepsilon, 9 \uparrow \Lambda$ & «1 & $r \cdot T, .70$ & الطلاقة الإجرائية بعدي & \\
\hline & & & $1,9.0$ & \& & $\mathrm{v} \wedge, \ldots$ & الطلاقة الاستراتيجية بعدي & \\
\hline & & & $r, \eta \varepsilon \gamma$ & $\varepsilon$ & $1 \leqslant 9,0$ Tा & التبرير التكيفي بعدي & \\
\hline & & & & $\varepsilon 7$ & $\varepsilon 9 r, 9+7$ & الفهم المفاهيمي بعدي & الكلي المصحح \\
\hline & & & & $\varepsilon 7$ & $\varepsilon V r, 910$ & الطلاقة الإجرائية بعدي & \\
\hline & & & & $\varepsilon\rceil$ & $1 \varepsilon \cdot, \lambda . q$ & الطلاقة الاستراتيجية بعدي & \\
\hline & & & & $\leq 7$ & $r 9 \varepsilon, 7 r_{\Lambda}$ & التبرير التكيفي بعدي & \\
\hline
\end{tabular}

يظهر من الجدول (ז ا) وجود فروق دالة إحصائياً عند مستوى الدلالة (م=0.05) وفقا لأثر المجموعة (تجريبية، ضابطة) في جميع الأبعاد، ولتحديد لصالح أي من مجموعتي الدراسة كانت الفروق الجوهرية، فقد تم حساب المتوسطات الحسابية المعدلة والأخطاء المعيارية للأبعاد وفقاً

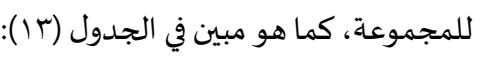

جدول (rا ): المتوسطات الحسابية المعدلة والأخطاء المعيارية للقياس البعدي لأبعاد اختبار الكفاءة الرياضية وفقاً للمجموعة

\begin{tabular}{|c|c|c|c|}
\hline الخطأ المعياري & المتوسط الحسابي المعدل & المجموعة & 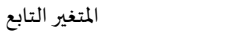 \\
\hline., $0 \leqslant \Lambda$ & $0, \lambda \cdot 1$ & تجريبية & \multirow[t]{2}{*}{ الفهم المفاهيهي بعدي } \\
\hline., 017 & $r, 0 \leqslant \varepsilon$ & ضابطة & \\
\hline . Eov & $7,\{\wedge \uparrow$ & تجرببية & \multirow[t]{2}{*}{ الطلاقة الإجرائية بعدي } \\
\hline . & $r, \varepsilon \cdot r$ & ضابطة & \\
\hline . & r, ETO & تجريبية & \multirow[t]{2}{*}{ الطلاقة الاستراتيجية بعدي } \\
\hline . r. ז. & 1, rN1 & ضابطة & \\
\hline . & $r, 770$ & تجريبية & \multirow[t]{2}{*}{ التبرير التكيفي بعدي } \\
\hline . & $1, \Lambda$. & ضابطة & \\
\hline
\end{tabular}

يتضح من الجدول (ب ا) أن الفروق الجوهرية بين المتوسطات الحسابية المعدلة للقياس البعدي في جميع أبعاد اختبار الكفاءة الرياضية

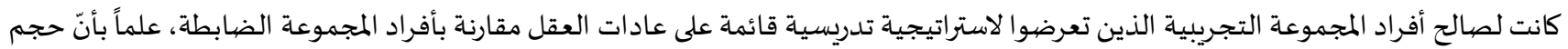




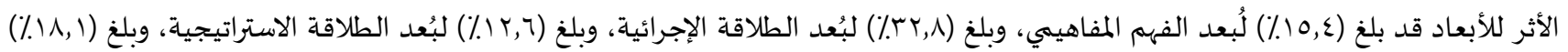

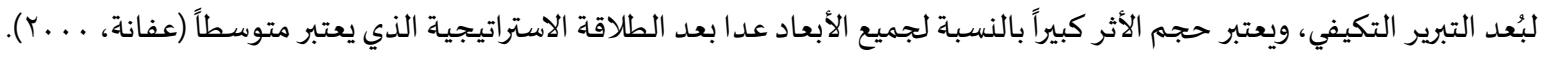

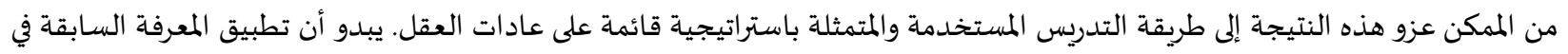

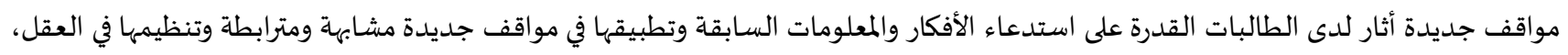

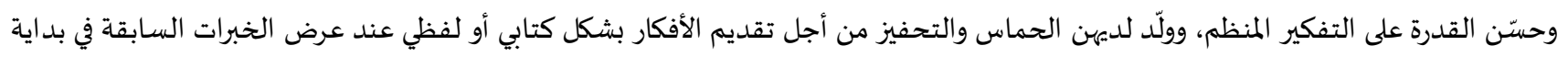

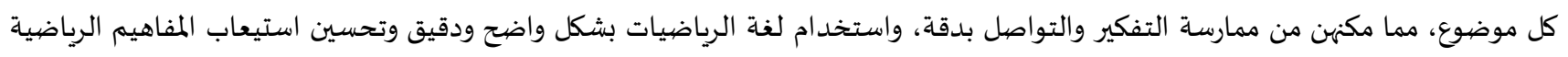

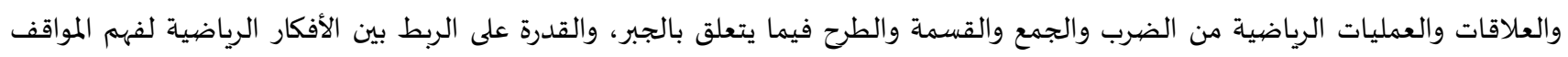

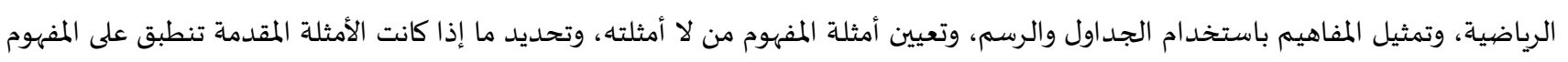

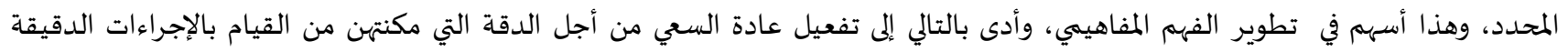

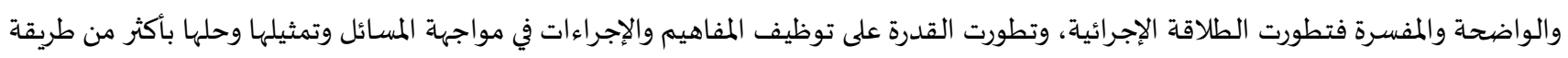

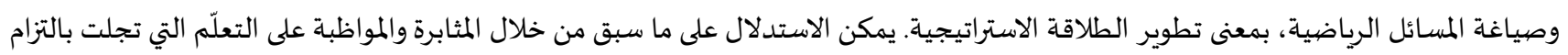

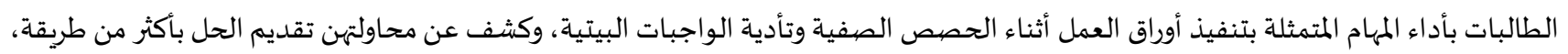

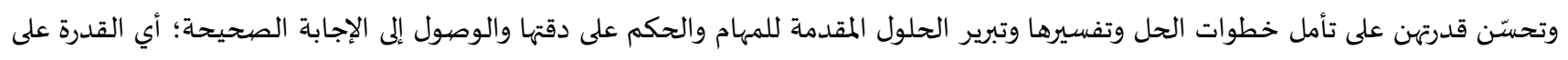
التبرير التكيفي.

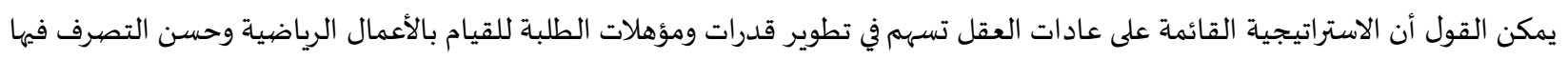

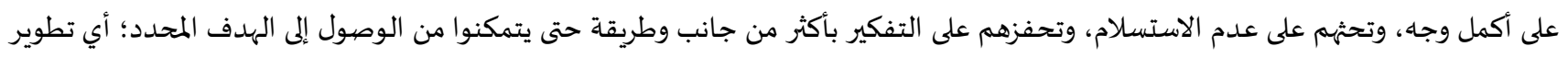
الكفاءة الرياضية.

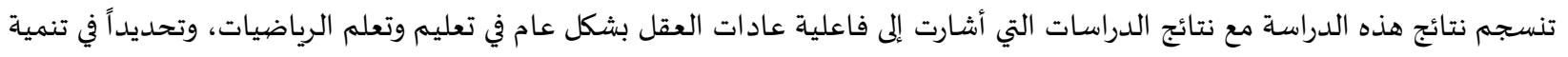

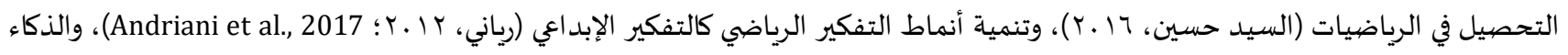

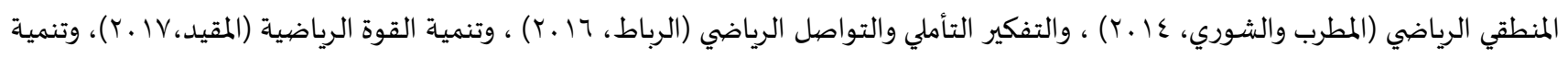
بعض مهارات التفكير الرياضي وحل المشكلات وفاعلية الذات (المبات (Poindexter, 2011).

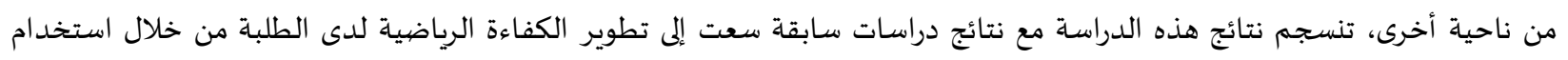

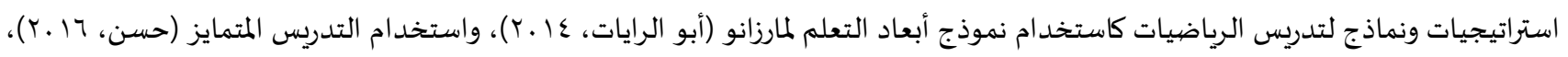

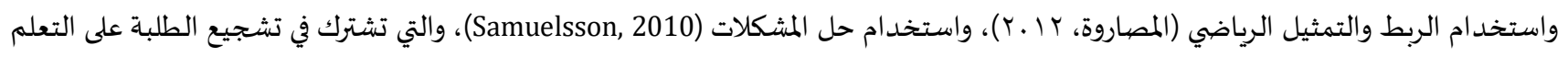

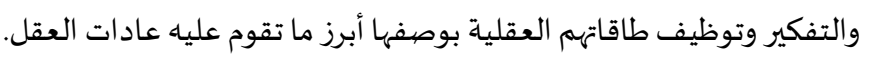

التوصيات والاقتراحات

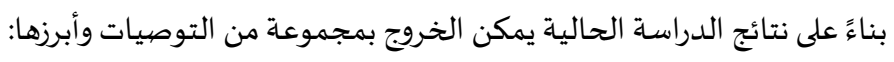

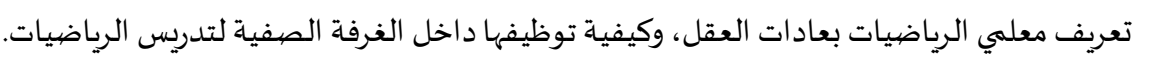

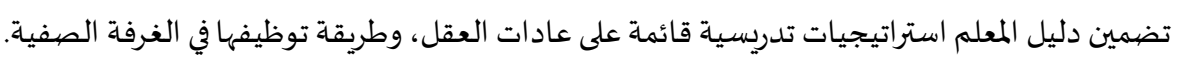

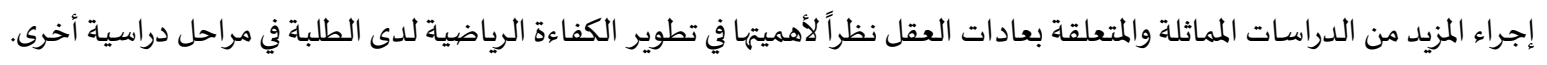

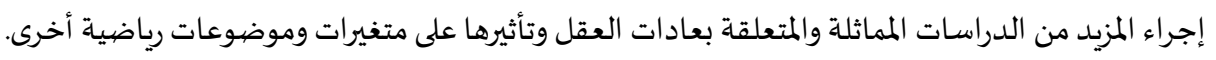

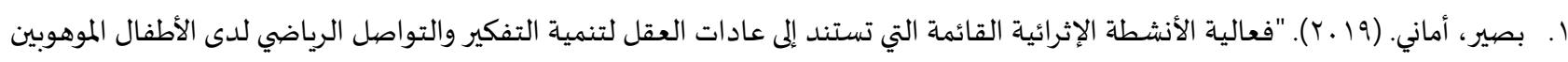

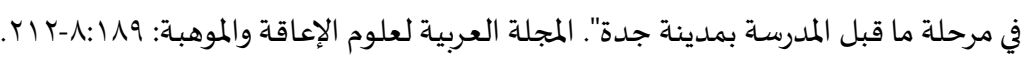

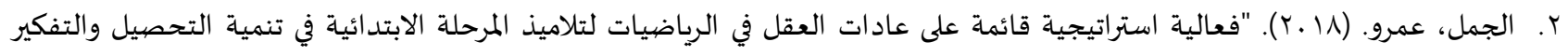

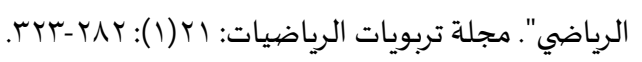

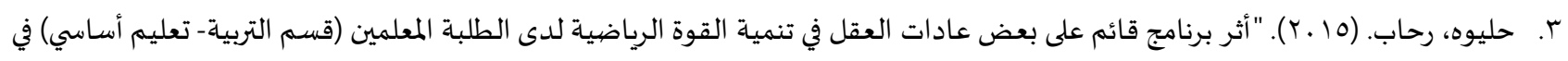

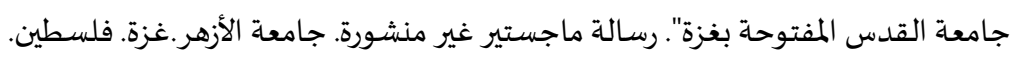


ع. أبو الرايات، علاء. (ع ا ـr). "فعالية استخدام نموذج أبعاد التعلم لمارزانو في تدريس الرياضيات على تنمية الكفاءة الرياضية لدى طلاب المرحلة

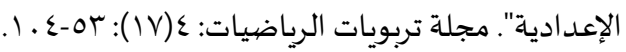

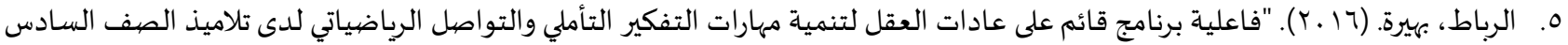

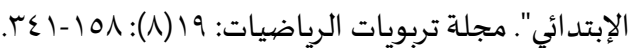

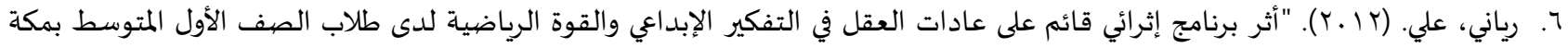
المكرمة". رسالة دكتوراه غير منشورة. كلية التربية. جامعة أم القرى. المملكة العربية السعودية.

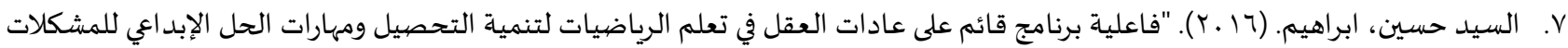
الرياضياة لدى تلاميذ المرحلة الإعد ادية". رسالة دكتوراه غير منشورة. كلية التربياة. جامعة بنها. مصر.

1. شيماء، حسن. (7 ا ـ ( ). "فاعلية برنامج قائم على استراتيجيات التدريس المتمايز في تنمية الكفاءة الرياضية لدى طلاب المرحلة الثانوية". مجلة

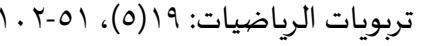

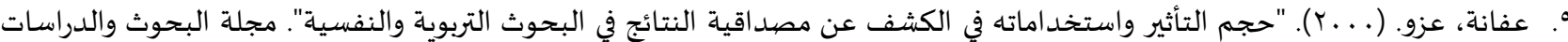

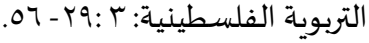

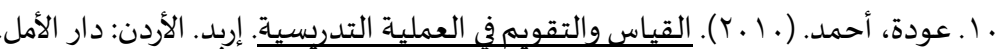

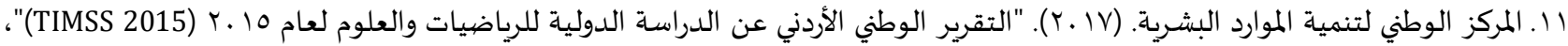

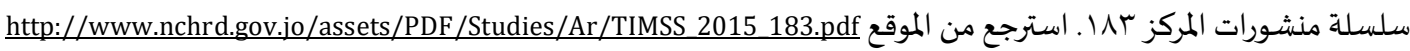

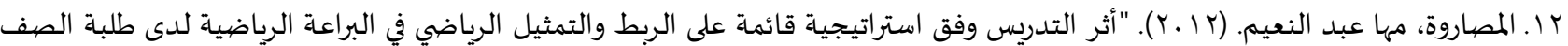
السادس الأسـاسي". رسالة ماجستير غير منشورة. الجامعة الهاشمية. الأردن.

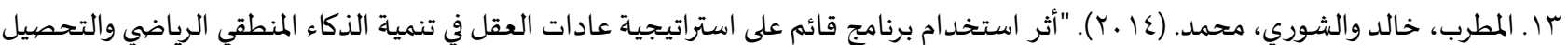

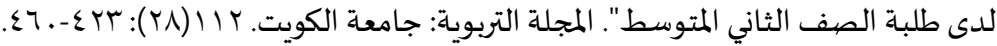
ع ا ـ المقيد، سامر. (V) ـ ا (Y). " فاعلية برنامج مقترح قائم على عادات العقل في تنمية القوة الرياضية لدى طلاب الصف الرابع الأساسي بغزة". رسالة ماجستير غير منشورة. الجامعة الإسلامية-غزة. فلسطين.

ثانياً: المراجع الأجنبية:

[1] Andriani, S., Yulianti, K., Ferdias, P., \& Fatinah, S. (2017). “The Effect of Mathematical Habits of Mind Learning Strategy Based on Problem Toward Students' Mathematical Creative Thinking Disposition". International E-Journal of Advances in Education. 3(9): 689-696, https://doi.org/10.18768/ijaedu.372122.

[2] Atakhyneh, B \& Aburiash, H. (2018). "Impact of Habits of Mind in Mathematical Creative thinking at Amman Schools". AnNajah University Journal for Research (Humanities). 32(2): 417-438, https://doi.org/10.35552/0247-032-002-008.

[3] Awofala, A.O.A. (2017). "Assessing senior secondary school student's mathematical proficiency as related to gender and performance in mathematics in Nigeria". International Journal of Research in Education and Science (IJRES). 3(2): 488502, https://doi.org/10.21890/ijres.327908.

[4] Costa, A., \& Kallick, B. (2000). Habits of mind: A developmental series. Alexandria, VA: Association for Supervision and Curriculum Development.

[5] Costa, A. L., \& Kallick, B. (2009). Habits of mind across the curriculum: Practical and creative strategies for teachers. ASCD.

[6] Cuoco, A., Goldenberg, E., \& Mark, J. (1996) "Habits of mind: An organizing principle for mathematics curricula". The Journal of Mathematical Behavior. 15(4): 375-402, https://doi.org/10.1016/s0732-3123(96)90023-1.

[7] Devaney, E., \& Yohalem, N. (2012). “Out-of-school time policy commentary: The Common Core Standards: What do they mean for out-of-school time, In Washington”. DC: The Forum for Youth Investment.

[8] Eccles, J., \& Wigfield, A. (1995). "In the mind of the actor: The structure of adolescents' achievement task values and expectancy-related beliefs". Personality and Social Psychology Bulletin. 21(3): 215-225, https://doi.org/10.1177/0146167295213003.

[9] Goldenberg, E. P. (1996). "Habits of mind as an organizer for the curriculum". Journal of Education, 178(1):13-34, https://doi.org/10.1177/002205749617800102

[10] Alhamlan, S., Aljasser, H., Almajed, A., Almansour, H., \& Alahmad, N. (2017). "A Systematic review: Using habits of mind to improve student's thinking in class". Higher Education Studies. 8(1): 25-35, https://doi.org/10.5539/hes.v8n1p25. 
[11] Johnson, R. (2012). "Developing habits of mind for numeracy in a low-literacy classroom: A focus on attitudes". MinneWiTESOL Journal. 29: 154-161

[12] Kallick, B. \& Zmuda, A. (2017). "Students at the center: Personalized learning with habits of mind". Association of Supervision and Curriculum Development (ASCD).

[13] Laswadi, Kusumah, Y., Darwis, S., \& Afgani, J. (2016). "Developing conceptual understanding and procedural fluency for junior high school students through model-facilitated learning (MFL)". European Journal of Science and Mathematics Education. 4(1): 67-74.

[14] Leikin, R. (2007). Habits of mind associated with advanced mathematical thinking and solution spaces of mathematical task, In the Proceedings of the Fifth Conference of the European Society for Research in Mathematics Education- CERME, 5, (pp. 2330-2339), Larnaca, Cyprus. Retrieved in 7 January, 2019 from http://ermeweb.free.fr/Cerme5.pdf.

[15] Lim, K., \& Selden, A. (2009). "Mathematical habits of mind", In S. L. Swars, Stinson, D. W., \& Lemons-Smith, S. (Eds.), Proceedings of the 31st Annual Meeting of the North American Chapter of the International Group for the Psychology of Mathematics Education, 5, pp.1576-1583), Atlanta: Georgia State University.

[16] MacGregor, D. (2013). Developing mathematical proficiency. EPS, Literacy and Intervention, Academy of Math.

[17] Mark, J., Cuoco, A., Goldenberg, E., \& Sword, S. (2010). “Contemporary curriculum issues: Developing mathematical habits of mind". Mathematics teaching in the Middle School. 15(9): 505- 509.

[18] National Research Council, Adding It Up: Helping Children Learn Mathematics, J.Kilpatric, J.Swafford, \& B.Findell (Eds), Mathematics Learning Study Committee, Center for Education, Division of Behavioral and Social Sciences and Education ,Washington, DC: The National Academies Press, (2001), https://doi.org/10.17226/9822.

[19] National Council of Teachers of Mathematics. (2000). "Principles and standards for school mathematics". Reston, VA: Author.

[20] Poindexter, C. (2011). "Teaching "habits of mind": Impact on students' mathematical thinking and problem-solving selfefficacy". Studies in Teaching 2011 Research Digest, (pp.97-102), Winston-Salem, NC: Wake Forest University.

[21] Samuelsson, J. (2010). "The impact of teaching approaches on students' mathematical proficiency in Sweden". International Electronic Journal of Mathematics Education. 5(2): 61-78.

[22] Schoenfeld, A. H. (2007). "What is Mathematical Proficiency and How Can It Be Assessed?", Assessing mathematical proficiency”. MSRI Publications. 53: 59-74, https://doi.org/10.1017/cbo9780511755378.008.

[23] Sommers, W. A., \& Olsen, W. (2010) "Habits of mind: Teacher's companion". The Institute for Habits of Mind. Education for a more thoughtful world. Retrieved in 8 January, 2019 from www.instituteforhabitsofmind.com.

[24] Wojcik, A. J. (2017) Developing Conceptual Understanding and Procedural Fluency in Algebra for High School Students with Intellectual Disability. Retrieved in 2 July 2019 from https://scholarscompass.vcu.edu/etd/5151. 
المجلة الدولية للدراسـات التربوبة والنفسية

International Journal of Educational \& Psychological Studies (EPS)

Journal Homepage: https://www.refaad.com/views/EPSR/Home.aspx

www.refaad.com

ISSN: 2520-4149 (Online) 2520-4130 (Print)

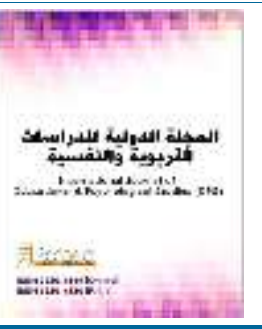

\title{
The effect of using a teaching strategy based on the habits of mind in the development of mathematical proficiency among primary stage students in Jordan
}

\begin{abstract}
${ }^{1}$ Rawan Ismail Al-Mefleh, ${ }^{2}$ Ma'moon Mohammed Al- Shannaq, ${ }^{3}$ Tariq Yousef Jawarneh
1 Student in the Department of Curriculum and Instruction, Faculty of Education, Yarmouk University

${ }^{2}$ Associate Professor in the Department of Curriculum and Instruction, Faculty of Education, Yarmouk University, Jordan

${ }^{3}$ Professor in the Department of Curriculum and Instruction, Faculty of Education, Yarmouk University, Jordan

1 rawanshdifat92@gmail.com ,2 mamoon.shannaq@yu.edu.jo, 3 tjawarneh@yu.edu.jo

Received Date : $15 / 2 / 2020$

Accepted Date : $25 / 3 / 2020$

DOI : https://doi.org/DOI:10.31559/EPS2020.8.2.7

Abstract: This study aimed to investigate the effect of using a Teaching Strategy Based on the Habits of Mind in the development of Mathematical Proficiency among Primary stage Students in Jordan. To achieve the objective of the study, the researchers prepared a test in mathematical proficiency and checked it for validity and reliability. An available sample consisting of (47) students was selected from an eighth-grade class in one school of the directorate of education in Al-Mafraq governorate. The sample was divided into two groups. One group consisting of (25) was randomly assigned as an experimental group and was taught the unit of "Algebra" through a Teaching Strategy Based on the Habits of Mind. The other group, consisting of (22) students was assigned as a control group and was taught the unit of "Algebra" through the traditional method. The mathematical proficiency test was administered to the students in the experimental and control groups before and after the experiment. The results revealed that there were statistically significant differences in mathematical proficiency among students attributed to the teaching method in favor of the students in the experimental group which was taught through Teaching Strategy Based on the Habits of Mind. In the light of the results, the researchers recommended the acquaintance of mathematics teachers of the Habits of mind and using them in teaching mathematics.
\end{abstract}

\section{Keywords: Habits of Mind; Mathematical Proficiency; Teaching Strategy.}

\section{References:}

[1] 'fanh, 'zw. (2000). "Hjm Altathyr Wastkhdamath Fy Alkshf 'n Msdaqyh Alnta'j Fy Albhwth Altrbwyh Walnfsyh". Mjlt Albhwth Waldrasat Altrbwyh Alflstynyh: $3: 29-56$.

[2] 'wdh, Ahmd. (2010). Alqyas Waltqwym Fy Al'mlyh Altdrysyh. Erbd. Alardn: Dar Alaml.

[3] Andriani, S., Yulianti, K., Ferdias, P., \& Fatinah, S. (2017). “The Effect of Mathematical Habits of Mind Learning Strategy Based on Problem Toward Students' Mathematical Creative Thinking Disposition". International E-Journal of Advances in Education. 3(9): 689-696, https://doi.org/10.18768/ijaedu.372122.

[4] Atakhyneh, B \& Aburiash, H. (2018). "Impact of Habits of Mind in Mathematical Creative thinking at Amman Schools". AnNajah University Journal for Research (Humanities). 32(2): 417-438, https://doi.org/10.35552/0247-032-002-008.

[5] Awofala, A.O.A. (2017). "Assessing senior secondary school student's mathematical proficiency as related to gender and performance in mathematics in Nigeria". International Journal of Research in Education and Science (IJRES). 3(2): 488502, https://doi.org/10.21890/ijres.327908.

[6] Bsyr, Amany. (2019). "F'alyt Alanshth Alethra'yh Alqa'mh Alty Tstnd Ela 'adat Al'ql Ltnmyh Altfkyr Waltwasl Alryady Lda Alatfal Almwhwbyn Fy Mrhlt Ma Qbl Almdrsh Bmdynt Jdh". Almjlh Al'rbyh L'lwm Ale'aqh Walmwhbh: 8:189-212.

[7] Costa, A., \& Kallick, B. (2000). Habits of mind: A developmental series. Alexandria, VA: Association for Supervision and Curriculum Development.

[8] Costa, A. L., \& Kallick, B. (2009). Habits of mind across the curriculum: Practical and creative strategies for teachers. ASCD. 
[9] Cuoco, A., Goldenberg, E., \& Mark, J. (1996) "Habits of mind: An organizing principle for mathematics curricula". The Journal of Mathematical Behavior. 15(4): 375-402, https://doi.org/10.1016/s0732-3123(96)90023-1.

[10] Devaney, E., \& Yohalem, N. (2012). "Out-of-school time policy commentary: The Common Core Standards: What do they mean for out-of-school time, In Washington". DC: The Forum for Youth Investment.

[11] Eccles, J., \& Wigfield, A. (1995). "In the mind of the actor: The structure of adolescents' achievement task values and expectancy-related beliefs". Personality and Social Psychology Bulletin. 21(3): 215-225, https://doi.org/10.1177/0146167295213003.

[12] Goldenberg, E. P. (1996). "Habits of mind as an organizer for the curriculum". Journal of Education, 178(1):13-34, https://doi.org/10.1177/002205749617800102.

[13] Alhamlan, S., Aljasser, H., Almajed, A., Almansour, H., \& Alahmad, N. (2017). "A Systematic review: Using habits of mind to improve student's thinking in class". Higher Education Studies. 8(1): 25-35, https://doi.org/10.5539/hes.v8n1p25.

[14] Hlywh, Rhab. (2015). "Athr Brnamj Qa'm 'la B'd 'adat Al'ql Fy Tnmyt Alqwh Alryadyh Lda Altlbh Alm'lmyn (Qsm AltrbyhT'elym Asasy) Fy Jam't Alqds Almftwhh Bghzh". Rsalt Majstyr Ghyr Mnshwrh. Jam't Alazhr. Ghzh. Flstyn.

[15] Aljml, 'Emrw. (2018). "F'alyt Astratyjyh Qa'mh 'la 'adat Al'ql Fy Alryadyat Ltlamyd Almrhlh Alabtda'yh Fy Tnmyt Althsyl Waltfkyr Alryady". Mjlt Trbwyat Alryadyat: 21(1): 282-323.

[16] Johnson, R. (2012). "Developing habits of mind for numeracy in a low-literacy classroom: A focus on attitudes". MinneWiTESOL Journal. 29: 154-161

[17] Kallick, B. \& Zmuda, A. (2017). "Students at the center: Personalized learning with habits of mind". Association of Supervision and Curriculum Development (ASCD).

[18] Laswadi, Kusumah, Y., Darwis, S., \& Afgani, J. (2016). "Developing conceptual understanding and procedural fluency for junior high school students through model-facilitated learning (MFL)". European Journal of Science and Mathematics Education. 4(1): 67-74.

[19] Leikin, R. (2007). Habits of mind associated with advanced mathematical thinking and solution spaces of mathematical task, In the Proceedings of the Fifth Conference of the European Society for Research in Mathematics Education- CERME, 5, (pp. 2330-2339), Larnaca, Cyprus. Retrieved in 7 January, 2019 from http://ermeweb.free.fr/Cerme5.pdf.

[20] Lim, K., \& Selden, A. (2009). "Mathematical habits of mind”, In S. L. Swars, Stinson, D. W., \& Lemons-Smith, S. (Eds.), Proceedings of the $31^{\text {st }}$ Annual Meeting of the North American Chapter of the International Group for the Psychology of Mathematics Education, 5, pp.1576-1583), Atlanta: Georgia State University.

[21] MacGregor, D. (2013). Developing mathematical proficiency. EPS, Literacy and Intervention, Academy of Math.

[22] Mark, J., Cuoco, A., Goldenberg, E., \& Sword, S. (2010). “Contemporary curriculum issues: Developing mathematical habits of mind". Mathematics teaching in the Middle School. 15(9): 505- 509.

[23] Almqyd, Samr. (2017). " Fa'lyt Brnamj Mqtrh Qa'm 'la 'adat Al'ql Fy Tnmyh Alqwh Alryadyh Lda Tlab Alsf Alrab' Alasasy Bghzh". Rsalt Majstyr Ghyr Mnshwrh. Aljam'h Aleslamyh- Ghzh. Flstyn.

[24] Almrkz Alwtny Ltnmyh Almward Albshryh. (2017). "Altqryr Alwtny Alardny 'n Aldrash Aldwlyh Llryadyat Wal'lwm L'am 2015 (Timss 2015)", Slslt Mnshwrat Almrkz $183 . \quad$ Astrj' $\quad$ Mn Almwq' Http://Www.NChrd.Gov.Jo/Assets/Pdf/Studies/Ar/Timss_2015_183.Pdf

[25] Almsarwh, Mha 'bd Aln'ym. (2012). "Athr Altdrys Wfq Astratyjyh Qa'mh 'la Alrbt Waltmthyl Alryady Fy Albra'h Alryadyh Lda Tlbt Alsf Alsads Alasasy". Rsalt Majstyr Ghyr Mnshwrh. Aljam'th Alhashmyh. Alardn.

[26] Almtrb, Khald Walshwry, Mhmd. (2014). "Athr Astkhdam Brnamj Qa'm 'la Astratyjyh 'adat Al'ql Fy Tnmyt Aldka' Almntqy Alryady Walthsyl Lda Tlbh Alsf Althany Almtwst". Almjlh Altrbwyh: Jam't Alkwyt. 112(28): 423-460.

[27] National Research Council, Adding It Up: Helping Children Learn Mathematics, J.Kilpatric, J.Swafford, \& B.Findell (Eds), Mathematics Learning Study Committee, Center for Education, Division of Behavioral and Social Sciences and Education ,Washington, DC: The National Academies Press, (2001), https://doi.org/10.17226/9822.

[28] National Council of Teachers of Mathematics. (2000). "Principles and standards for school mathematics". Reston, VA: Author.

[29] Poindexter, C. (2011). "Teaching "habits of mind": Impact on students' mathematical thinking and problem-solving selfefficacy". Studies in Teaching 2011 Research Digest, (pp.97-102), Winston-Salem, NC: Wake Forest University.

[30] Abw Alrayat, 'la'. (2014). "F'alyt Astkhdam Nmwdj Ab'ad Alt'lm Lmarzanw Fy Tdrys Alryadyat 'la Tnmyt Alkfa'h Alryadyh Lda Tlab Almrhlh Ale'dadyh". Mjlt Trbwyat Alryadyat: 4(17): 53-104.

[31] Alrbat, Bhyrh. (2016). "Fa'lyt Brnamj Qa'm 'la 'adat Al'ql Ltnmyt Mharat Altfkyr Altamly Waltwasl Alryadyaty Lda Tlamyd Alsf Alsads Alebtda'y". Mjlt Trbwyat Alryadyat: 19(8): 158-341.

[32] Ryany, 'ly. (2012). "Athr Brnamj Ethra'y Qa'm 'la 'adat Al'ql Fy Altfkyr Alebda'y Walqwh Alryadyh Lda Tlab Alsf Alawl Almtwst Bmkh Almkrmh". Rsalt Dktwrah Ghyr Mnshwrh. Klyt Altrbyh. Jam't Am Alqra. Almmlkh Al'rbyh Als'wdyh. 
[33] Samuelsson, J. (2010). "The impact of teaching approaches on students' mathematical proficiency in Sweden". International Electronic Journal of Mathematics Education. 5(2): 61-78.

[34] Schoenfeld, A. H. (2007). "What is Mathematical Proficiency and How Can It Be Assessed?", Assessing mathematical proficiency”. MSRI Publications. 53: 59-74, https://doi.org/10.1017/cbo9780511755378.008.

[35] Shyma', Hsn. (2016). "Fa'lyt Brnamj Qa'm 'la Astratyjyat Altdrys Almtmayz Fy Tnmyt Alkfa'h Alryadyh Lda Tlab Almrhlh Althanwyh". Mjlt Trbwyat Alryadyat: 19(5), 51-102.

[36] Sommers, W. A., \& Olsen, W. (2010) "Habits of mind: Teacher's companion". The Institute for Habits of Mind. Education for a more thoughtful world. Retrieved in 8 January, 2019 from www.instituteforhabitsofmind.com.

[37] Alsyd Hsyn, Abrahym. (2016). "Fa'lyt Brnamj Qa'm 'la 'adat Al'ql Fy T'lm Alryadyat Ltnmyt Althsyl Wmharat Alhl Alebda'y Llmshklat Alryadyh Lda Tlamyd Almrhlh Ale'dadyh". Rsalt Dktwrah Ghyr Mnshwrh. Klyt Altrbyh. Jam't Bnha. Msr.

[38] Wojcik, A. J. (2017) Developing Conceptual Understanding and Procedural Fluency in Algebra for High School Students with Intellectual Disability. Retrieved in 2 July 2019 from https://scholarscompass.vcu.edu/etd/5151. 